\title{
Phylogenomics and evolution of floral traits in the Neotropical tribe Malmeeae (Annonaceae)
}

\author{
J.C. Lopes ${ }^{\mathrm{a}, *, 1}$, L.W. Chatrou ${ }^{\mathrm{b}}$, R. Mello-Silva ${ }^{\mathrm{a}}$, P.J. Rudall ${ }^{\mathrm{c}}$, M.G. Sajo ${ }^{\mathrm{d}}$ \\ a Universidade de São Paulo, Instituto de Biociências, Departamento de Botânica, Rua do Matão, 277, 05508-090 São Paulo, SP, Brazil \\ b Wageningen University and Research, Biosystematics Group, Droevendaalsesteeg 1, 6708 PB Wageningen, The Netherlands \\ ${ }^{c}$ Royal Botanic Gardens, Kew, Richmond, Surrey TW9 3AB, UK \\ d Universidade Estadual Paulista, Instituto de Biociências, Departamento de Botânica, Avenida 24A, 13506-900 Rio Claro, SP, Brazil
}

\section{A R T I C L E I N F O}

\section{Keywords:}

Ancestral state analysis

Androdioecy

Floral morphology

Next-generation sequencing

\begin{abstract}
A B S T R A C T
Androdioecy is the rarest sexual system among plants. The majority of androdioecious species are herbaceous plants that have evolved from dioecious ancestors. Nevertheless, some woody and androdioecious plants have hermaphrodite ancestors, as in the Annonaceae, where androdioecious genera have arisen several times in different lineages. The majority of androdioecious species of Annonaceae belong to the Neotropical tribe Malmeeae. In addition to these species, Pseudoxandra spiritus-sancti was recently confirmed to be androdioecious. Here, we describe the morphology of male and bisexual flowers of Pseudoxandra spiritus-sancti, and investigate the evolution of androdioecy in Malmeeae. The phylogeny of tribe Malmeeae was reconstructed using Bayesian inference, maximum parsimony and maximum likelihood of 32 taxa, using DNA sequences of 66 molecular markers of the chloroplast genome, sequenced by next generation sequencing. The reconstruction of ancestral states was performed for characters associated with sexual systems and floral morphology. The phylogenetic analyses reconstructed three main groups in Malmeeae, (Malmea (Cremastosperma, Pseudoxandra)) sister to the rest of the tribe, and (Unonopsis (Bocageopsis, Onychopetalum)) sister to (Mosannona, Ephedranthus, Klarobelia, Oxandra, Pseudephedranthus fragrans, Pseudomalmea, Ruizodendron ovale). Hermaphroditism is plesiomorphic in the tribe, with four independent evolutions of androdieocy, which represents a synapomorphy of two groups, one that includes three genera and 14 species, the other with a single genus of seven species. Male flowers are unisexual from inception and bisexual flowers possess staminodes and functional stamens. Pseudoxandra spiritussancti is structurally androdioecious.
\end{abstract}

\section{Introduction}

Although the great majority of flowers are bisexual, approximately $10 \%$ of angiosperm species have unisexual flowers (Barrett, 2002). Unisexual flowers can originate either by organ abortion, with the gynoecium or androecium primordia ceasing to develop at an early stage (type I), or from inception, when only stamen or carpel primordia are initiated (type II, Mitchell and Diggle, 2005). In type II, abortion of sexual organs can occur at different stages, either at an early stage in stamen or carpel development, or before or after meiosis. A common plant hormone signaling pathway controls the abortion of both gynoecium and androecium primordia (Di Stilio et al., 2005). Genes involved in organ primordium initiation and organ identity, such as Band C-class genes, can also regulate the development of unisexual flowers from inception of sexual organs (Diggle et al., 2011).
Unisexual flowers occur in a wide range of sexual systems, including monoecy, andro- and gynomonoecy, dioecy and andro- and gynodioecy. In monoecious systems, male and female flowers grow on the same plant; andromonoecious plants possess bisexual and male flowers and gynomonoecious plants have bisexual and female flowers. In dioecious systems, some plants produce exclusively female flowers and others only male ones; in gynodioecious systems, female and bisexual flowers grow in different plants; androdioecious plants produce exclusively male or bisexual flowers (Bawa and Beach, 1981). Androdioecious taxa are rare (Pannell, 2002) because for males to persist in the population they must have the ability to produce twice as many descendants as the hermaphrodites (Charlesworth, 1984; Lloyd, 1975). Moreover, the evolutionary pathway that originates androdioecious species is complex (Barrett, 2002; Ross, 1982). In most cases, androdioecious plants have originated from dioecious ancestors; they are

\footnotetext{
* Corresponding author.

E-mail address: jenifer.clopes@gmail.com (J.C. Lopes).

${ }^{1}$ This work is part of the PhD thesis of J.C. Lopes. Further authors are in alphabetical order.
} 
herbaceous and form populations that suffer recurrent local extinction followed by re-colonization (Pannell, 2001, 2002). Nevertheless, some androdioecious species have hermaphrodite ancestors and are woody plants, such as species of Oleaceae and Tapisciaceae (Ishida and Hiura, 1998; Lepart and Dommée, 1992; Wallander, 2008; Zhou et al., 2016).

Annonaceae, a pantropical family with 2440 species in 109 genera, is a woody family with hermaphrodite ancestors; in this family, androdioecy has evolved in several different lineages (Saunders, 2010; Chatrou et al., 2012). The majority of androdioecious taxa are included in tribe Malmeeae (subfamily Malmeioideae), a Neotropical group. Malmeeae was recovered as monophyletic by Pirie et al. (2006), including 13 genera, six of which with androdioecious species. Three major groups are recognized in the tribe, although the relationships among them remain unclear. Because of its phylogenetic uncertainty, it is difficult to hypothesize the evolution of androdioecy in the tribe. In this paper, we reconstruct the phylogeny of the tribe Malmeeae from DNA sequences of 66 chloroplast molecular markers, and use results to investigate the evolution of sexual systems in this tribe. We describe the morphology of male and bisexual flowers of the androdioecious species Pseudoxandra spiritus-sancti (Annonaceae-Malmeoideae-Malmeeae).

\section{Material and methods}

\subsection{Phylogenomics and evolution of androdieocy}

\subsubsection{Taxon sampling}

A total of 27 species from tribe Malmeeae were sampled. The number of species sampled by genus and the total of species in each genus are: Cremastosperma R.E.Fr. 2/35, Ephedranthus S. Moore 2/7, Klarobelia Chatrou 1/12, Malmea R.E.Fr. 2/6, Mosannona Chatrou 2/14, Onychopetalum R.E.Fr. 1/2, Oxandra A. Rich. 9/30, Pseudomalmea Chatrou 1/3, Pseudoxandra R.E.Fr. 5/24, Ruizodendron R.E.Fr. 1/1, and Unonopsis R.E.Fr. 1/48. Five taxa, including one Magnoliaceae, one Anaxagoreoideae, two Annonoideae, and one Malmeoideae represent the outgroup species (Table 1, Fig. S1).

\subsubsection{DNA extraction and sequencing}

Total genomic DNA was extracted from $20 \mathrm{mg}$ of leaves dried in silica gel or from herbarium material using cetyl trimethyl ammonium bromide (CTAB) method (Doyle and Doyle, 1987). The genomic DNA was purified using the Wizard ${ }^{\circledR}$ DNA Clean-Up System following the manufacturer's instructions (Promega, The Netherlands).

The samples were sent to Beijing Genomics Institute, Hong Kong, China, to be sequenced via Illumina platform in two lanes, and for library preparation. After verification of the concentration, sample integrity and purification, $1.5 \mu \mathrm{g}$ DNA was fragmented in 500 bp by Covaris, then the Gel-Electrophotometric was used to test the fragmented DNA. The fragmented DNA was combined with End Repair Mix, incubated at $20^{\circ} \mathrm{C}$ for $30 \mathrm{~min}$. The end-repaired DNA was purified with QIAquick PCR Purification Kit (Qiagen). A-Tailing Mix was then added and incubated at $37^{\circ} \mathrm{C}$ for $30 \mathrm{~min}$. The purified Adenylate $3^{\prime}$ Ends DNA, Adapter and Ligation Mix were combined and incubated at $20^{\circ} \mathrm{C}$ for 15 min. Adapter-ligated DNA was selected by running a $2 \%$ agarose gel to recover the target fragments. The gel was purified with QIAquick Gel Extraction kit (Qiagen). Several rounds of PCR amplification with PCR Primer Cocktail and PCR Master Mix were performed to enrich the Adapter-ligated DNA fragments. Then the PCR products were selected by running another $2 \%$ agarose gel to recover the target fragments. The gel was purified again with QIAquick Gel Extraction kit (Qiagen).

The final library was quantified by determining the average molecule length using the Agilent 2100 bioanalyzer instrument (Agilent DNA 1000 Reagents), and by quantifying the library by real-time quantitative PCR (QPCR) (TaqMan Probe).

The qualified libraries were amplified on cBot to generate the cluster on the flowcell (HiSeq PE Cluster Kit v4 cBot, Illumina). The amplified flowcell was sequenced paired end on the HiSeq 2500 System
(HiSeq SBS Kit V4, Illumina).

The above library preparation protocol described refers to the normal library preparation. For the sample with low amount of DNA, less than $1 \mu \mathrm{g}$ of DNA, low input library preparation and WGA treatment were used. The low input library preparation follows the same protocol mentioned above with some changes in the selection of fragmented DNA, PCR enzyme and an increase in the PCR cycles number. The WGA treatment uses the REPLI- ${ }^{\circledast}{ }^{\circledR}$ Midi Kit (Qiagen) as a first step before the normal library preparation.

\subsubsection{Chloroplast genome assembly and molecular sampling}

The chloroplast genome assembly was performed using the Interactive Organelle Genome Assembly (IOGA) pipeline (Bakker et al., 2016). The raw sequence data, forward and reverse, for each sample was used as input and genomes of different taxa, including Liriodendron tulipifera L. (Magnoliaceae), were the references. The best assemblies, those with the best Assembly Likelihood Estimation (Clark et al., 2013), were used as the final assembly. The best assemblies for each sample were input in Geneious R8 (Kearse et al., 2012) and mapped and annotated to Liriodendron tulipifera (GenBank accession DQ899947). Gene annotations were extracted in Geneious R8. Gene sequences for samples that could not be retrieved in the way cited above were accessed by BLAST (Altschul et al., 1990).

\subsubsection{Sexual system and morphological characters}

The species analysed are either hermaphrodite or androdioecious, and ancestral states of the sexual system were inferred using Bayesian and parsimony analyses. (Character 1, Table 2). Other morphological characters were sampled because of their importance in delimitation of the genera involved (Table 2, Doyle and Le Thomas, 1996; Koek-Noorman et al., 1990), allowing investigation of their role in a phylogenetic context. A broader analysis of the evolution of morphological characters in Annonaceae was presented by Doyle and Le Thomas (1996).

Character states were scored using Maas and Westra (1984, 1985, Anaxagorea), Pontes et al. (2004, Annona), Maas et al. (2007, Bocageopsis, Onychopetalum, and Unonopsis), Pirie (2005, Cremastosperma) Safford (1916, Desmopsis) Oliveira and Sales (1999, Ephedranthus), Lopes and Mello-Silva (unpublished data, Ephedranthus), Chatrou (1997, 1998, Klarobelia, Malmea, Mosannona, and Pseudomalmea), Chen and Nooteboom (1993, Magnolia), Paul Hoekstra (unpublished data, Monanthotaxis), Junikka et al. (2016, Oxandra) Erkens et al. (2017, Pseudephedranthus, and Ruizodendron), Maas and Westra (2003, 2005, Pseudoxandra), and Westra and Maas (2012, Tetrameranthus) (Table S1).

\subsubsection{Ancestral state analysis}

The evolution of sexual system and morphological characters in Malmeeae was inferred by estimating the marginal posterior probability of ancestral states in a Bayesian framework. This approach allows the incorporation of phylogenetic uncertainty during the inference, by taking a sample of different trees generated during the Bayesian phylogenetic analyses for estimating the ancestral states in each node (Pagel et al., 2004). Ancestral states were estimated using BayesTraits V2 (Pagel and Meade, 2014). The analyses were performed for each character separately, using the module MultiState as implemented in BayesTraits and the sample of 1000 post-burn-in trees. Initially, a maximum likelihood analysis was run to derive an empirical prior. For characters with two states, two hypotheses were tested, which consider respectively equal and different rates of transformation from state 0 to state 1 and from 1 to 0 . A third model tested characters with three or more states, with symmetrical rates of transformation. The rate of transformation from state 0 to state 1 is equal to the rate from 0 to 2 and from 1 to 2 , the remaining rates, from state 1 to state 0 , from 2 to 0 , and from 2 to 1 , are different (Table S2). To test which of these models fit the data best, comparisons among them were done using the Akaike information criterion corrected for small data (Sugiura, 1978) implemented on R (R Development Core Team, 2008). 
Table 1

Species of Malmeeae and outgroups sampled for the phylogenetic analyses.

\begin{tabular}{|c|c|c|}
\hline Taxon & Origin & Voucher \\
\hline \multicolumn{3}{|l|}{ Outgroup } \\
\hline Magnolia kobus DC. & Japan & Chatrou 93 (U) \\
\hline Anaxagorea phaeocarpa Mart. & Ecuador - Napo & Maas $8592(\mathrm{U})$ \\
\hline Annona sp. nov. & Neotropics & Maas $8759(\mathrm{U})$ \\
\hline Monanthotaxis buchananii (Engl.) Verdc. & Tanzania & Bidgood 2706 (WAG) \\
\hline Desmopsis bibracteata (B.L.Rob) Saff. & Costa Rica & Chatrou 728 (WAG) \\
\hline \multicolumn{3}{|l|}{ Tribe Malmeeae } \\
\hline Cremastosperma cauliflorum R.E.Fr. & Peru - Loreto & Chatrou 224 (U) \\
\hline Cremastosperma leiophyllum R.E.Fr. & Bolivia - Santa Cruz & Pirie $2(\mathrm{U})$ \\
\hline Ephedranthus guianensis R.E.Fr. & Guyana & Scharf $64(\mathrm{U})$ \\
\hline Ephedranthus amazonicus R.E.Fr. & Peru - Loreto & Chatrou 173 (U) \\
\hline Klarobelia inundata Chatrou & Peru - Loreto & Chatrou 205 (U) \\
\hline Malmea dielsiana R.E.Fr. & Peru - Madre de Dios & Chatrou $122(\mathrm{U})$ \\
\hline Malmea dimera Chatrou & Panama - Panama & Croat 34626 (U) \\
\hline Mosannona costaricensis (R.E.Fr.) Chatrou & Costa Rica - Limón & Chatrou $90(\mathrm{U})$ \\
\hline Mosannona discolor (R.E.Fr.) Chatrou & Guyana & Jansen-Jacobs $6000(\mathrm{U})$ \\
\hline Onychopetalum periquino (Rusby) D.M. Johnson \& N.A. Murray & Bolivia - Beni & Chatrou $425(\mathrm{U})$ \\
\hline Oxandra asbeckii (Pulle) R.E.Fr. & Guyana & University of Guyana, course Neotropical Botany UG-NB-55 (U) \\
\hline Oxandra espintana (Spruce ex Benth.) Baill. & Peru - Madre de Dios & Chatrou $133(\mathrm{U})$ \\
\hline Oxandra euneura Diels & Peru - Loreto & Chatrou 235 (U) \\
\hline Oxandra guianensis R.E.Fr. & Guyana & Scharf $67(\mathrm{U})$ \\
\hline Oxandra laurifolia (Sw.) A.Rich. & Dominican Republic & Maas 8375 (U) \\
\hline Oxandra longipetala R.E.Fr. & Costa Rica - Osa & Chatrou $114(\mathrm{U})$ \\
\hline Oxandra macrophylla R.E.Fr. & Peru - Loreto & Chatrou 204 (U) \\
\hline Oxandra martiana (Schltdl.) R.E.Fr. & Brazil - Espírito Santo & Lopes 363 (SPF) \\
\hline Oxandra polyantha R.E.Fr. & Peru - Loreto & Chatrou 215 (U) \\
\hline Pseudomalmea diclina (R.E.Fr.) Chatrou & Peru - Madre de Dios & Chatrou 136 (U) \\
\hline Pseudoxandra angustifolia Maas & Peru - San Martín & Pirie $139(\mathrm{U})$ \\
\hline Pseudoxandra bahiensis Maas & Brazil - Bahia & Lopes 414 (SPF) \\
\hline Pseudoxandra lucida R.E.Fr. & Peru - Loreto & Chatrou $212(\mathrm{U})$ \\
\hline Pseudoxandra obscurinervis Maas (1) & Brazil - Amazonas & Martins 15 (INPA) \\
\hline Pseudoxandra obscurinervis Maas (2) & Brazil - Amazonas & Webber s.n. (U) \\
\hline Pseudoxandra spiritus-sancti Maas & Brazil - Espírito Santo & Lopes 436 (SPF) \\
\hline Ruizodendron ovale (Ruiz \& Pav.) R.E.Fr. & Ecuador - Napo & Maas $8600(\mathrm{U})$ \\
\hline Unonopsis pittieri Saff. & Costa Rica - Braulio Carillo & Chatrou $68(\mathrm{U})$ \\
\hline
\end{tabular}

Character 5 (number of ovules), with four states, was analysed with the reversible jump strategy, a faster and more efficient algorithm for characters with four states. Bayesian analyses were run with a Markov chain Monte Carlo approach, an exponential hyper prior of 0-20, 20 million generations, sampling every 1000th generation, discarding the first 5 million generations (25\%) as burn-in. Ancestral states were estimated for all nodes, except for character 4 (petal aestivation) in which the analysis was done just for nodes of interest. For nodes with posterior probability less than 1.0, the MRCA (most recent common ancestor) command was applied (Pagel et al., 2004). The results of ancestral state reconstruction are shown in the Bayesian consensus tree. Phylograms and posterior probabilities graphs were elaborated using $R(R$ Development Core Team, 2008).

\subsubsection{Phylogenetic analyses}

One challenge that emerges with the analysis of a large data matrix generated by next generation sequencing is to choose the best way to partition and analyse the data. The best partition scheme was algorithmically chosen with a priori partition into codon position for protein coding genes (Lanfear et al., 2014; Kainer and Lanfear, 2015) for preventing misleading results with high resolution and support values for clades that are in fact unsupported (Simmons, 2014). For parsimony analysis, the RATCHET, an algorithm that reduce the risk of the analysis getting stuck in a suboptimal tree island, was used to improve the analysis search (Nixon, 1999a).

\subsubsection{Data partition and selection of substitution model}

The selection of the best partitioning scheme and substitution model for each partition was performed in PartitionFinder v1.1.1 (Lanfear et al., 2012). This software compares numerous partitioning schemes and selects the optimal one. The alignment was divided into codon positions for the 64 protein coding genes, 192 data bocks were created, plus the two intergenic region (psbA-trnH and trnL-trnF) in a total of 194 data blocks (Table S3, molecular markers). The data blocks were then

Table 2

Characters analysis and coding. D\&LT = Doyle and Le Thomas (1996), vH = van Heusden (1992), and vS\&K = van Setten and Koek-Noorman (1992).

\begin{tabular}{|c|c|c|c|c|}
\hline Characters & States & & & \\
\hline 1 - Sexual system & Hermaphrodite $(0)$ & Androdioecious (1) & & \\
\hline 2 - Midrib (D\&LT) & Concave or flat: $(0)$ & Convex: (1) & & \\
\hline 3 - Flower number (D\&LT) & Always one, rarely two: (0) & One to many: (1) & & \\
\hline 4 - Petal aestivation $(\mathrm{vH})$ & Imbricate: $(0)$ & Valvate: (1) & & \\
\hline 5 - Ovule (D\&LT) & More than six: $(0)$ & Two to five: (1) & Always two: (2) & One: (3) \\
\hline 6 - Stigma (D\&LT) & Lobed: $(0)$ & Capitate: $(1)$ & Cylindrical: (2) & \\
\hline 7 - Stamen morphology (D\&LT) & Laminar: (0) & Narrow with tongue-like extension connective: (1) & Peltate-truncate: (2) & \\
\hline 8 - Staminodes $(\mathrm{vH})$ & Absent: $(0)$ & Present: (1) & & \\
\hline 9 - Endosperm (vS\&K) & ribbon-shaped (0) & Peg-shaped (1) & Spiniform (2) & Lamellate (3) \\
\hline
\end{tabular}




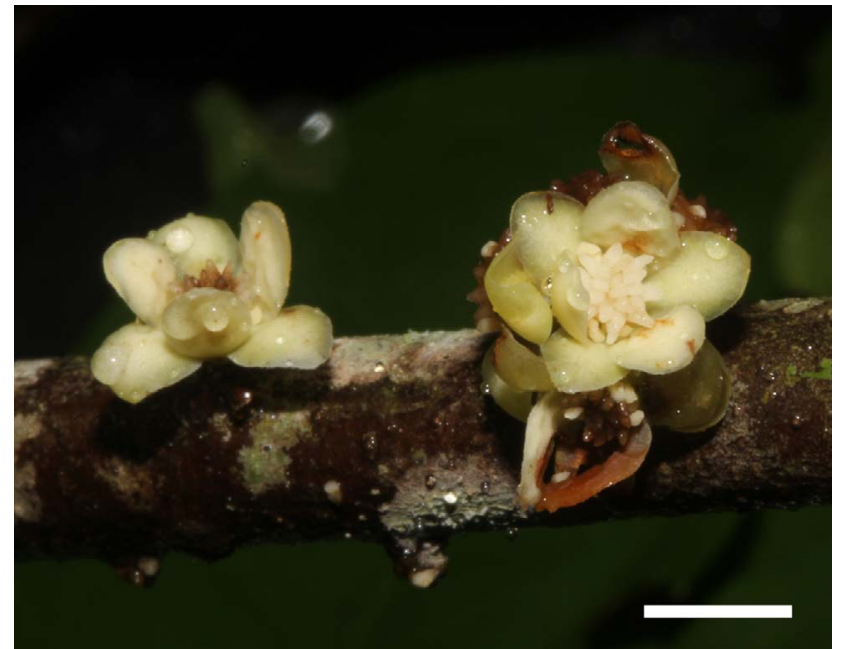

Fig. 1. Bisexual flowers of Pseudoxandra spiritus-sancti. Photo: Alexandre Zuntini. Bar $=1.0 \mathrm{~cm}$.

submitted to relaxed clustering algorithm (search = rcluster), a heuristic algorithm that analyses a user-defined percentage of all possible partition schemes and the respective substitution model. The substitution models analysed were GTR $+\mathrm{G}$ and GTR $+\mathrm{I}+\mathrm{G}$. The chosen percentage of $30 \%$ optimizes results and computational time (Lanfear et al., 2014). This approach was chosen due to the large number of possibilities to be analysed, 38,175 data subsets, which were generated with the 194 data blocks. The best partition scheme was identified using the Bayesian information criterion (BIC).

\subsubsection{Matrix}

For phylogenetic analyses, 66 molecular markers were used. The first data set ('complete)' contained 33 accessions that are nearly complete for all markers. A second data set ('supermatrix') contained six additional accessions with data for only three markers, $p s b \mathrm{~A}-t r n \mathrm{H}$, $r b c \mathrm{~L}$ and $t r n \mathrm{~L}-t r n \mathrm{~F}$ (Table S3). These six samples were taken from Pirie et al. (2006) and were selected to improve the taxonomic sampling, two Malmeeae species from genera not yet sampled, (Bocageopsis pleiosperma and Pseudephedranthus fragrans), two from genera with only one species already sampled, (Klarobelia cauliflora and Unonopsis rufescens), a species with uncertain phylogenetic placement, (Oxandra venezuelana), and one member of subfamily Ambavioideae, (Tetrameranthus duckei). Alignments were performed using MAFFT (Katoh et al., 2002) in Geneious R8 package (Kearse et al., 2012) and were checked in Mesquite (Maddison and Maddison, 2015). Data concatenation was done with SequenceMatrix, version 1.78 (Vaidya et al., 2011). The alignment of the supermatrix contained 65,002 characters, the complete matrix 64,898.

\subsubsection{Maximum Likelihood (ML) analysis}

For maximum likelihood (ML) analysis the RAxML (Stamatakis, 2014) web-server program was used at the CIPRES portal in San Diego, CA, USA (Miller et al., 2010, http://www.phylo.org/portal2). A rapid bootstrap analysis (Stamatakis et al., 2008) and search for the bestscoring ML tree were conducted in one single program run (-f a). The option "let RaxML halt bootstrapping automatically" was select and the bootstrapping criterion was the extended majority rule consensus tree (-N autoMRE). The substitution model selected was GTRGAMMA under 13 partitions as recovered by PartitionFinder (Table S4; Lanfear et al., 2012).

\subsubsection{Bayesian Inference (BI)}

Two Bayesian analyses were conducted in MrBayes 3.2.6 (Ronquist et al., 2012) one of them via CIPRES platform (Miller et al., 2010). For each analysis, two independent analyses were run (nruns $=2$ ) with three heated chains and one cold chain (nchain $=4$ ). The first $25 \%$ of samples from the cold chain were discarded as burn-in. The number of generations of the Markov chain Monte Carlo was 71,204,000 generations for the analysis with 33 plus six samples and 100 million generations for the analysis with 33 samples. This difference is due to the CIPRES platform in which the first analysis was performed. Both analyses were set to 100 million generations, however when the first analysis reached 168 CPUs hours it was stopped by the system; the second one ran in a private computer and completed the number of generations set. Both the print and sample frequencies were set to 1000 for the first analysis and to 5000 for the second. The data were partitioned following the results obtained by PartitionFinder (Table S4, Lanfear et al., 2012). The substitution model GTR (nst $=6$ ) was set for each partition, with gamma shape distribution frequencies and invariants sites for some of the partitions, as described in the partition scheme results (Table S4).

\subsubsection{Maximum Parsimony (MP) analysis}

Matrix for parsimony analysis was derived from the 65,002 characters matrix used for ML and BI analyses with 33 plus six samples, from which 61,669 uninformative characters were excluded, and nine morphological characters were included (Tables 2 and S1), resulting in a matrix with 3342 characters. The exclusion of uninformative characters had the goal to speed up the processing time of the analysis. Data concatenation and edition were performed on Winclada (Nixon, 1999b). Parsimony analyses were conducted using TNT (Goloboff et al., 2003). First, a tree bisection reconnection (TBR) analysis was performed. To improve the search for the most parsimonious trees, the RATCHET was implemented with 100 iterations and five seeds and default settings (Nixon, 1999a). Standard bootstrap analysis was performed with 1000 replications. Ambiguous transformations are indicated in text, and shown as ACCTRAN in the cladogram.

\subsection{Flower morphology}

\subsubsection{Taxon sampling}

Pseudoxandra spiritus-sancti (Fig. 1) was collected in its natural habitat. Trees ranging from 5 up to $15 \mathrm{~m}$ height occur through the Atlantic Forest in the Espírito Santo State, Brazil. The vouchers Lopes 319, with male flower, and Lopes 436, with bisexual flower, are deposited in the herbaria CVRD and SPF (acronyms according to Thiers, 2017).

\subsubsection{Light and scanning electron microscopy}

Buds and flowers were fixed using 70\% formalin-acetic alcohol (FAA) and subsequently stored in 70\% ethanol. For the floral morphological studies, buds were dissected in $70 \%$ alcohol under a stereomicroscope, critical-point dried using an Autosamdri-815B criticalpoint dryer, mounted on aluminium stubs with carbon discs and coated with platinum in a Quorum Q150T sputter-coater. Samples were examined and images were taken using a Hitachi $S-4700$ cold field emission scanning electron microscope (SEM). Analyses of flower morphology were complemented examining floral anatomy. Floral buds were dehydrated in butanol and embedded in Paraplast using standard methods. Prepared material were serially sectioned at $\mathrm{ca}$ $13 \mu \mathrm{m}$ thickness, stained in safranin and Alcian blue, dehydrated through an ethanol series to $100 \%$ ethanol, transferred to Histoclear, and mounted in DPX mounting medium (distrene, with dibutyl phthalate and xylene). Slides were examined using a Leica DMLB photomicroscope fitted with a Zeiss Axiocam digital camera. Images were processed and illustrations prepared using Adobe Photoshop (Redwood City, CA). 


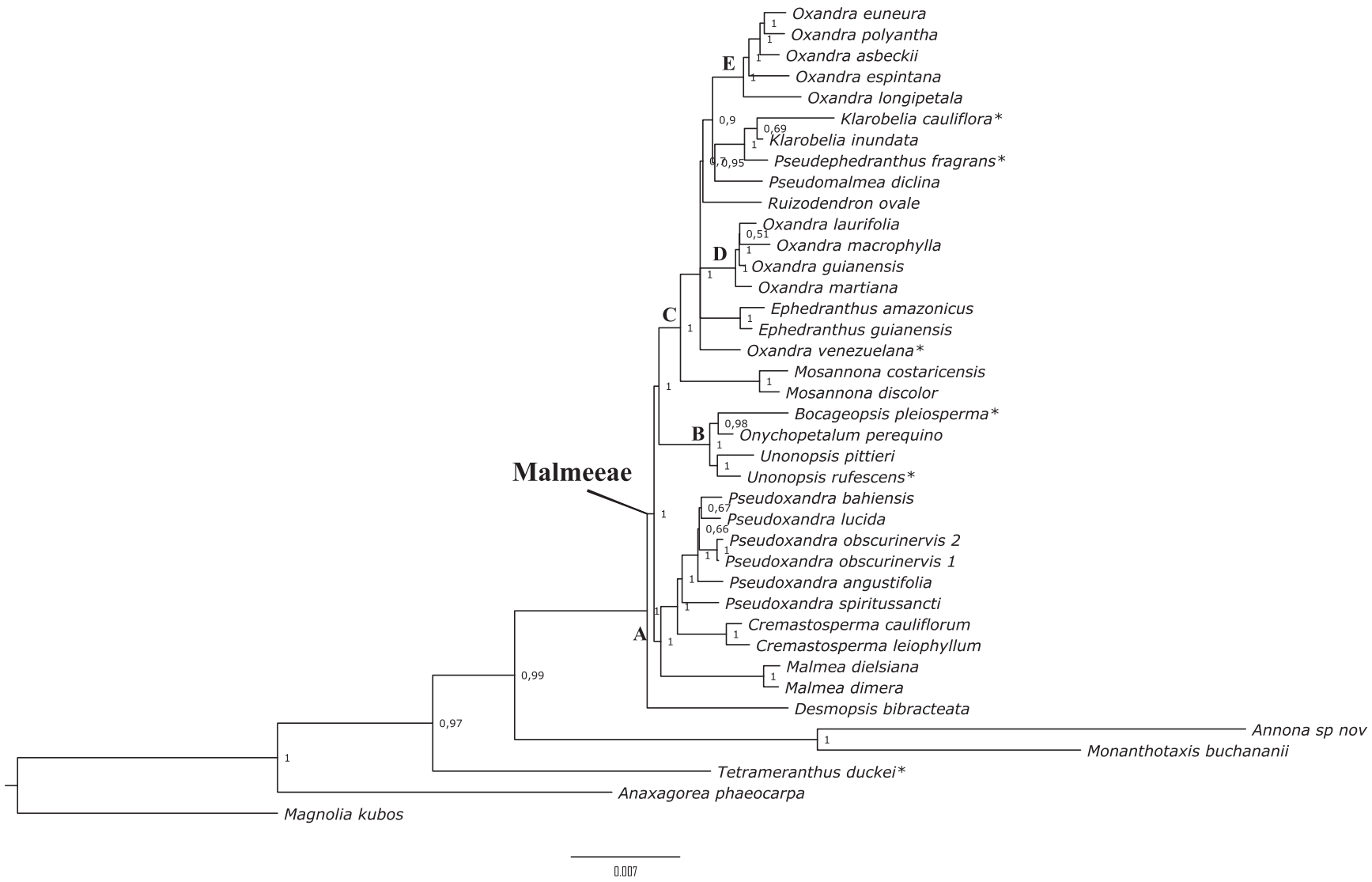

Fig. 2. Consensus tree from Bayesian Inference analysis. Asterisks $(*)$ denote species with incomplete data. Letters in the nodes are cited in the text.

\section{Results}

\subsection{Phylogenomics and evolution of androdioecy}

\subsubsection{Data partition and selection of substitution model}

The best partition scheme has 13 subsets. Table S4 shows the partition subsets and substitution models for each subset.

\subsubsection{Phylogenetic relationship}

The consensus tree of the Bayesian inference (BI) analysis with 33 plus six samples is shown in Fig. 2. The BI analysis with just the 33 samples with complete dataset is presented in Fig. S2. The majority rule consensus tree generated from maximum likelihood (ML) analysis is showed in Fig. S3. Three most parsimonious trees were found with 5565 steps each. Strict consensus tree is showed on Fig. 3.

The Bayesian inference (BI) analysis of the supermatrix (Fig. 2) has recovered a similar topology as the analysis of the complete dataset, (Fig. S2), showing that the addition of incompletely sampled species does not produce limitation. The three types of phylogenetic analyses each have recovered three highly supported groups in tribe Malmeeae, 0.95 of posterior probability (PP) in BI analysis and more than $95 \%$ bootstrap support (BS) in ML and maximum parsimony (MP) analyses (Figs. 2, S3, and 3). Tribe Malmeeae is monophyletic (1.0 BI, 86\% ML, $87 \% \mathrm{MP}$ ) and supported by imbricate petals (character 4: state 0, ambiguously homoplastic/two possible optimizations), and spiniform rumination (9:2, homoplastic), with a change to valvate petals in Unonopsis, Bocageopsis, Onychopetalum group, and two changes each to lamellate and peg-shaped rumination (Fig. 3). Malmea sister to Cremastosperma and Pseudoxandra (1.0 BI, 98\% ML, 88\% MP) are sister to the remaining genera. Pseudoxandra emerged as monophyletic, supported by narrow stamen with tongue-like extension connective (7:1, homoplastic), with $P$. spiritus-sancti sister to the rest of the species (1.0 BI, 94\% ML, 88\% MP). ((Unonopsis (Bocageopsis, Onychopetalum))
(Mosannona (Ephedranthus, Klarobelia cauliflora (oxandra laurifolia group ((((Pseudephedranthus, Klarobelia inundata) Pseudomalmea) oxandra eunera group) (Ruizodendron, Oxandra venezuelana)))))) is supported by convex midrib (2:1, ambiguously homoplastic) (1.0 BI, 94\% ML, 90\% MP). Bocageopsis and Onychopetalum sister to Unonopsis is supported by many flowers (3:1, homoplastic), valvate petals (4:1, ambiguously homoplastic), cylindrical stigma (6:2 homoplastic), and narrow stamen with tongue-like connective extension $(7: 1$, homoplastic, change in Unonopsis rufescens) (1.0 BI, 100\% ML, 98\% MP; node B, Figs. 2, S3, and 3). Mosannona is monophyletic and supported by lamellate rumination (9:3, homoplastic) (1.0 BI, 100\% ML, 100\% MP). Mosannona sister to (Ephedranthus, Klarobelia cauliflora (oxandra laurifolia group ((((Pseudephedranthus, Klarobelia inundata) Pseudomalmea) oxandra eunera group) (Ruizodendron, Oxandra venezuelana)))) is supported by concave to flat midrib (2:0, ambiguously homoplastic, reversal in Pseudephedranthus and in oxandra eunera group) (node C, Figs. 2, S3, and 3). In this polytomy there are two highly supported groups of Oxandra, (( (O. laurifolia, O. macrophylla) O. guianensis) $O$. martiana), the oxandra laurifolia group (1.0 BI, 100\% ML, 75\% MP; node D, Figs. 2, S3, and 3), and ((( (O. euneura, O. polyantha) $O$. asbeckii) $O$. espintana) $O$. longipetala), the oxandra euneura group, supported by convex midrib (2:1, ambiguously homoplastic) (1.0 BI, 100\% ML, 99\% MP; node E, Figs. 2, S3, and 3). ((Ruizodendron ovale, Oxandra venezuelana) ((Pseudomalmea diclina (Pseudephedranthus fragrans, Klarobelia inundata)) oxandra euneura group)) is supported by lamellate rumination (9:3, homoplastic) with a change to peg-shaped rumination in oxandra euneura group (0.7 BI, 53\% ML, 2\% MP). The group (Pseudomalmea diclina (Pseudephedranthus fragrans, Klarobelia inundata)) is supported by androdioecy (1:1, homoplastic) (0.95 BI, 48\% ML, 11\% MP), which also supports Ephedranthus (1.0 BI, 100\% ML, 100\% MP).

Klarobelia cauliflora is not placed together with $K$. inundata in the ML and MP phylogenies, but in the polytomy that includes Ephedranthus, both groups of Oxandra, Pseudephedranthus fragrans, Pseudomalmea, and 


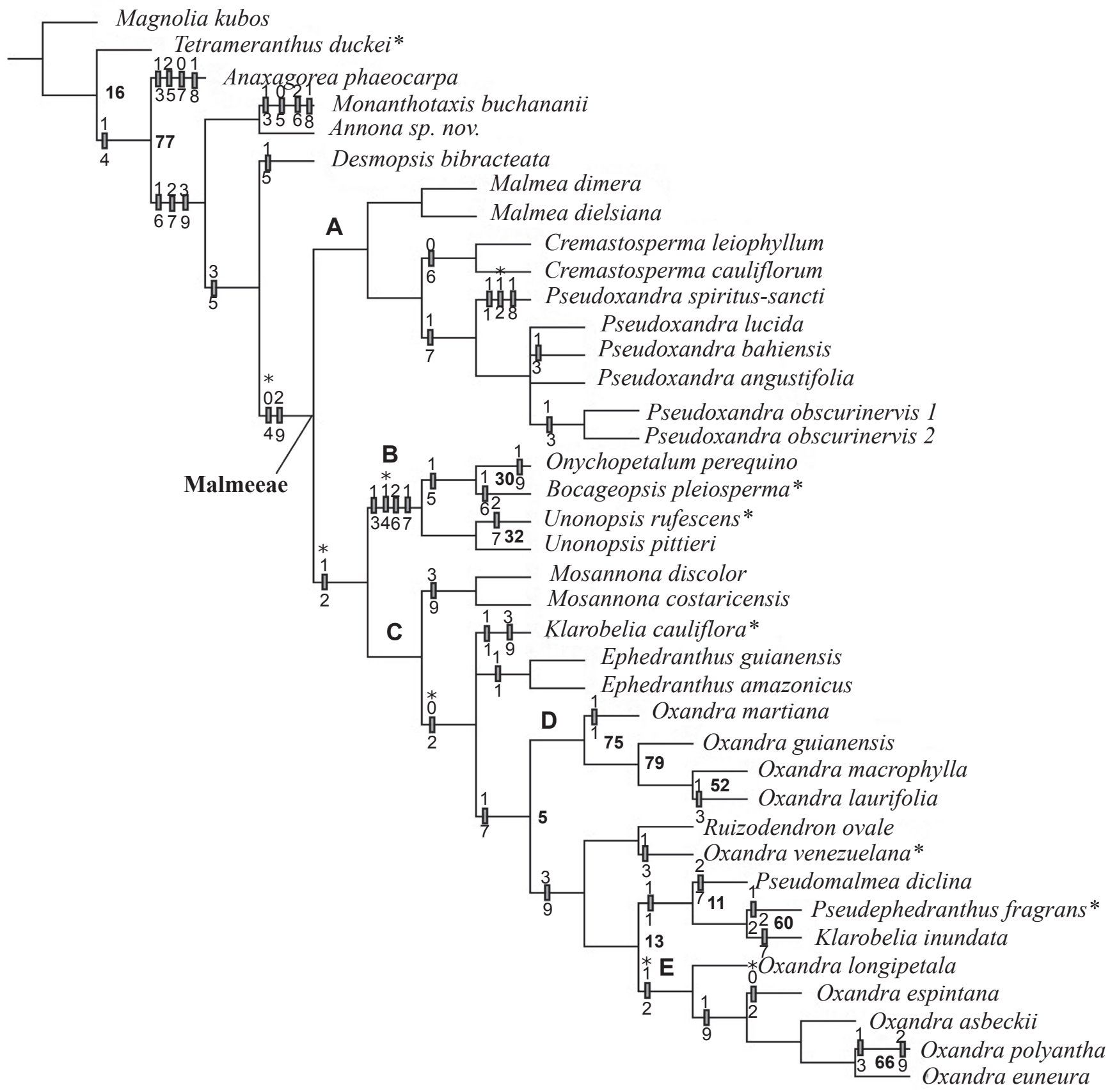

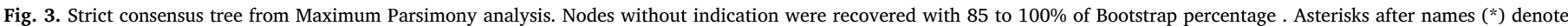

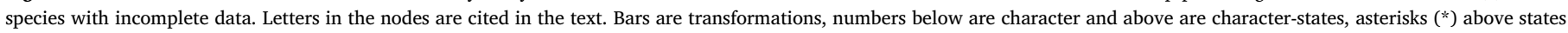
indicate transformations with ambiguous optimization.

Ruizodendron ovale (Figs. S3 and 3). Nevertheless, Klarobelia cauliflora emerges as sister to $K$. inundata in the Bayesian analysis (0.7 BI; Fig. 2). Oxandra venezuelana has a different position in each analysis. It is part of a polytomy, together with Ephedranthus, Klarobelia, Oxandra, Pseudephedranthus fragrans, Pseudomalmea, and Ruizodendron ovale, in the Bayesian analysis (Fig. 2), is sister to Ephedranthus in the Maximum Likelihood phylogeny (Fig. S3), and is sister to Ruizodendron ovale in the Parsimony analysis (Fig. 3). Ruizodendron ovale is sister to (oxandra euneura group ((Klarobelia, Pseudephedranthus fragrans) Pseudomalmea diclina)) in BI and ML analyses (0.7 BI, 53\% ML; Figs. 2 and S3).

\subsubsection{Ancestral state analysis}

The reconstruction of the sexual system shows that the ancestral state in Malmeeae is hermaphroditism (Fig. 4A, node 6, PP 0.97). The analysis indicates that the ancestral state at the crown node of the clade formed by Klarobelia, Pseudephedranthus, Pseudomalmea, Ruizodendron, and Oxandra espintana group is hermaphroditism, with moderate posterior probability (Fig. 4A, node 11, PP 0.72). The analysis also suggests that in addition to this clade androdioecy has evolved an additional three times, in Ephedranthus (node 19), Oxandra martiana, and Pseudoxandra spiritus-sancti. It is unlike that androdioecy has appeared earlier than node 9, indicating that there must have been here three independent origins (Fig. 4A).

A concave to flat midrib is the ancestral condition in the tribe (Fig. 4B, node 6, PP 0.90). A convex midrib is present in (Unonopsis (Bocageopsis, Onychopetalum)), node 24, Mosannona, node 23, and the oxandra euneura group, node 15 . Their more recent common ancestor has a convex midrib (Fig. 4B, node 8, PP 0.73). Similarly, all species of 


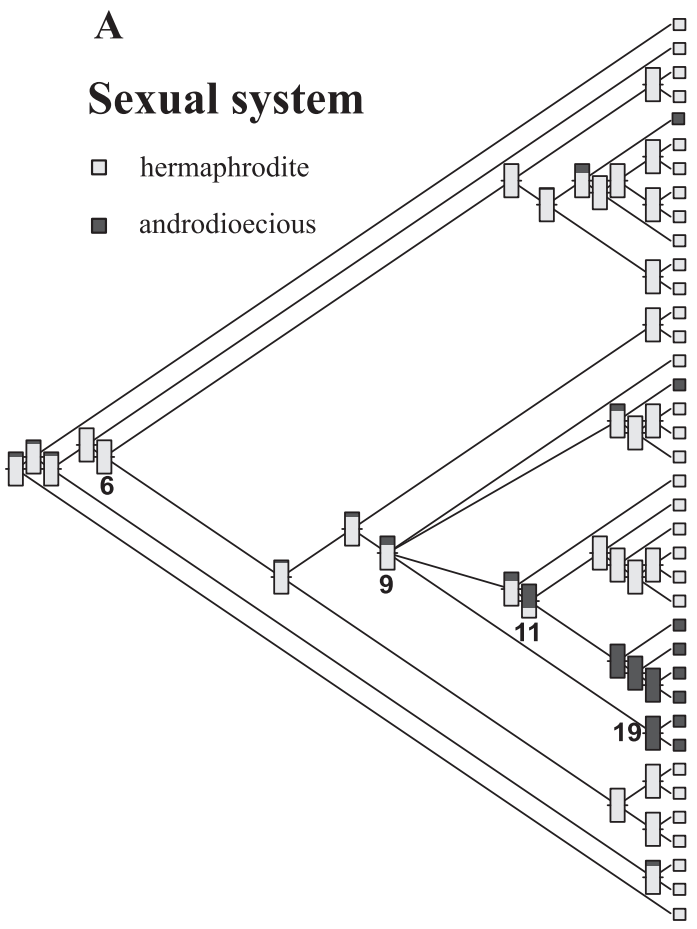

Te trameranthus ducke Desmopsis bibracteata Malm e a dim era Malm e a dielsiana Pseudoxandra spiritus sancti Ps eudoxandra obscurine rvis Pseudoxandra obscurinervis 2 Pseudoxandra lucida Pseudoxandra bahiens is Pseudoxandra angus tifolia Crem as tos perm a le io phyllum Mosannona discolor Mosannona costaricensis Oxandravenezuelana Oxandra martiana Oxandra m a crophylla Oxandra la urifolia Oxandra guianens is $R$ uizodendron ovale Oxandra longipe ta la Oxandra es pintana Oxandra polyantha Oxandra euneura Oxandra as becki Pseudom alm e a diclin seudephedranthus fragrans Kla ro be lia in und ata Klarobe lia ca uliflora Ephedranthus guianens is
Ephedranthus amazonicus Unonops is rufescens

Unonops is pittieri Onychopetalum perequino Bocageops is pleios perm Monanthotaxis buchananii Annona sp. nov. Anaxagorea phaeocarpa

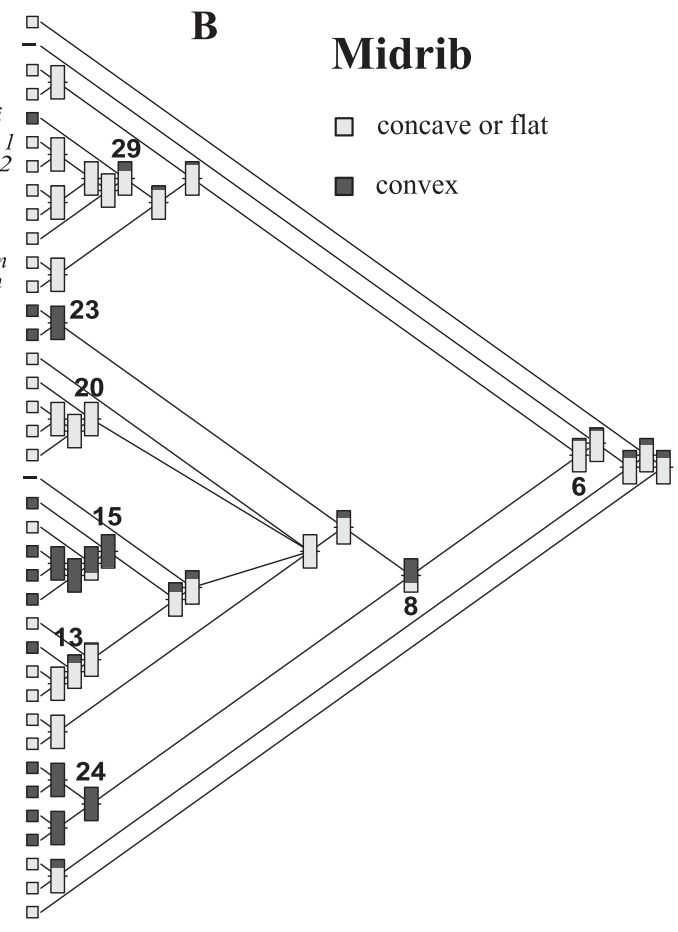

D

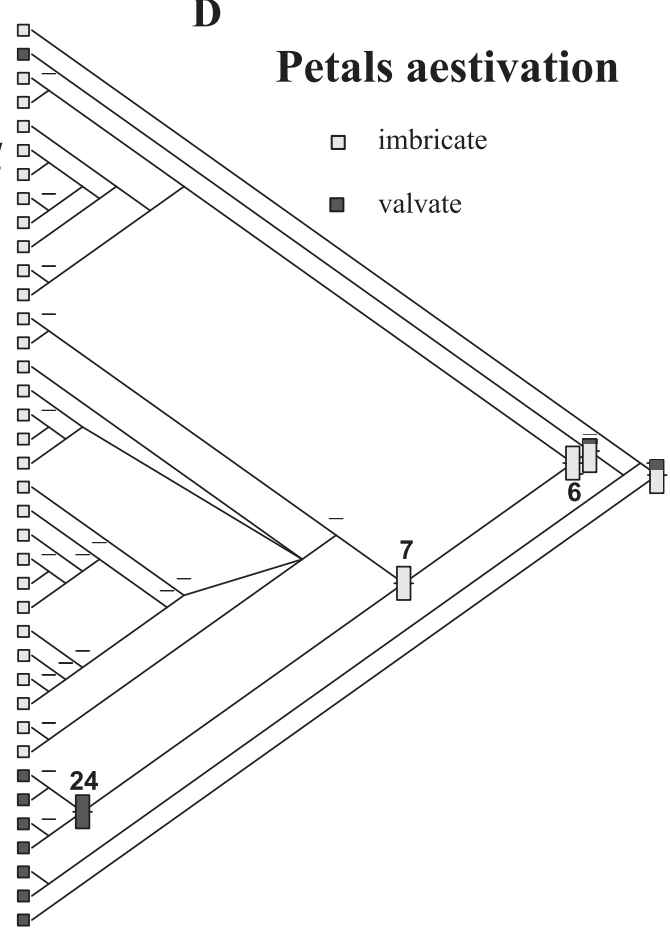

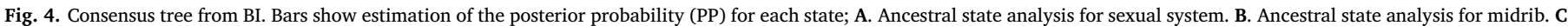
Ancestral state analysis for flower number. D. Ancestral state analysis for petal aestivation.

the oxandra euneura group except $O$. espintana possess a convex midrib, the ancestral state estimated for this group (Fig. 4B, node 15, PP 0.96). In Pseudoxandra, only $P$. spiritus-sancti has a convex midrib, and the most recent common ancestor was estimated to have a concave midrib (Fig. 4B, node 29, PP 0.70).

Solitary flowers were estimated to be ancestral in the tribe (Fig. 4C, node 6 , PP 0.95), and the character has changed five times in the evolutionary history of Malmeeae. The ancestral condition that includes all tribe members except Malmea, Cremastosperma, and Pseudoxandra, was estimated as possessing uncertain character state (Fig. 4C, node 7). The presence of many flowers represents a synapomorphy of (Unonopsis (Bocageopsis, Onychopetalum)) Fig. 4C, node 24, PP 0.99).

Imbricate petals are ancestral in Malmeeae (Fig. 4D, node 6, PP 0.99); (Unonopsis (Bocageopsis, Onychopetalum)) has valvate petals (Fig. 4D, node 24, PP 0.99). It is unlikely that valvate petals have arisen previously in Malmeeae because the posterior probability of this state in 

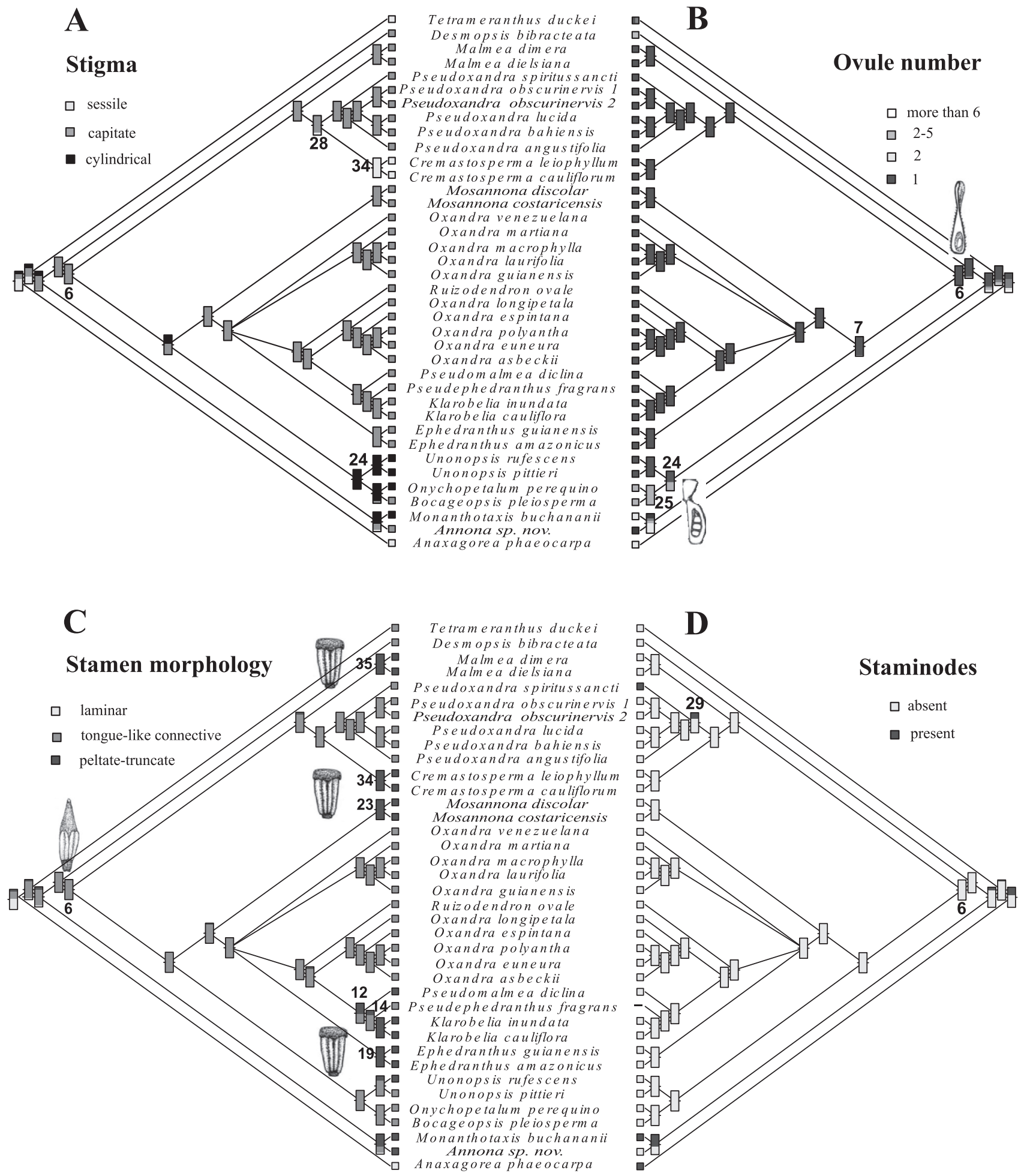

Te trameranthus duckei Desmops is bibracteato Malme a dim e ra Pseudoxandra spiritus ancti Pseudoxandra obscurinervis Pseudoxandra obscurinervis
Ps eudoxandra lucida Pseudoxandra bahiens is Pseudoxandra angus tifolia Crem as tos perm a le io $p$ hyllum Crem as tos perm a cauliflorum re $m$ as to s perm a ca a liflo
Mosannona discolar Mosannona discolar
Mosannona costaricensi Mosannona costaricens
Oxandra ve ne zuelana Oxandra martiana Oxandra macrophylla Oxandra la urifolia Oxandra guianens is $R$ uizodendron ovale Oxandra longipe ta la Oxandra espintana Oxandra polyantha Oxandra euneura Pseudom alme a diclin Pse dom alme a diclina Klarobelia in und ata Kla ro be lia ca uliflora Ephedranthus guianens is Ehedranthus amazonicus Unonops is rufescens Unonops is pittieri

Onychopetalum perequino Bocageops is pleios perm a Monanthotaxis buchanani Annonasp. nov.

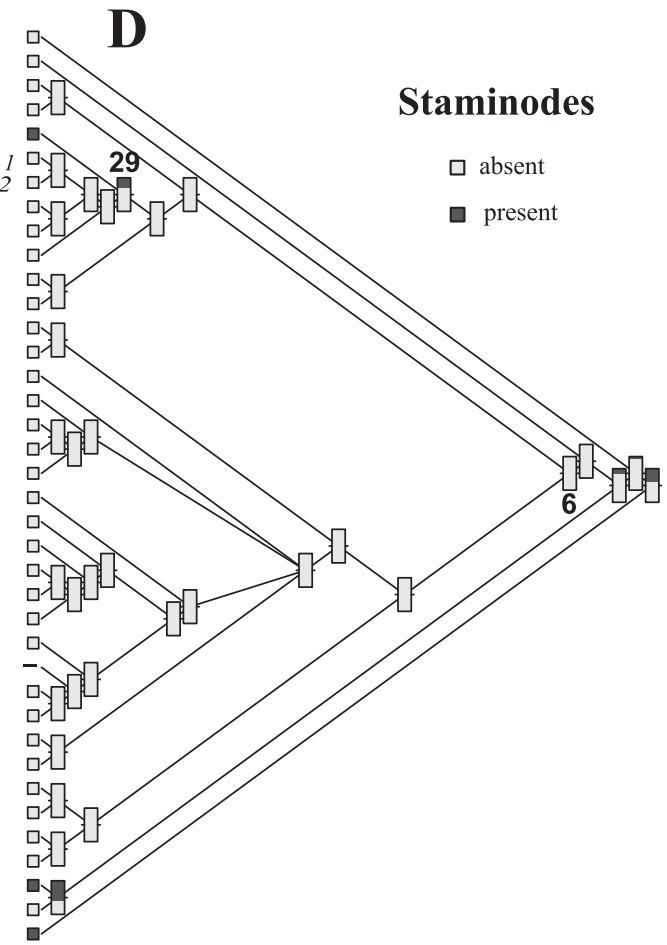

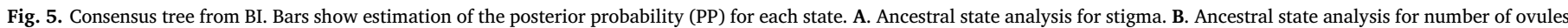
per carpel. C. Ancestral state analysis for stamen morphology. D. Ancestral state analysis for staminodes. Drawings from van Heusden (1992).

the preceding node is zero (Fig. 4D, node 7).

Within the tribe, a cylindrical stigma is a synapomorphy of (Unonopsis (Bocageopsis, Onychopetalum)) (Fig. 5A, node 24, PP 0.98), with a reversal in Bocageopsis. A lobed stigma in Cremastosperma (Fig. 5A, node 34) was estimated to have evolved within the ancestor of the genus (PP 0.99) and not before, because the ancestral state was estimated to be a capitate stigma (Fig. 5A, node 28, PP 0.84 ). One ovule per carpel and a capitate stigma are ancestral in Malmeeae
(Fig. 5B and A, node 6, respectively PP 0.99 and 0.95 ). Two to five ovules per carpel are found only in Bocageopsis and Onychopetalum (Fig. 5B, node 25). One ovule per carpel remained ancestral up to node 7 (Fig. 5B, PP 0.93).

Within the tribe, stamens can be narrow, with a tongue-like connective, the ancestral state (Fig. 5C, node 6 PP 0.99), or peltate-truncate, which has evolved seven times independently within the tribe, in Cremastosperma (node 34), Ephedranthus (node 19), Klarobelia (node 

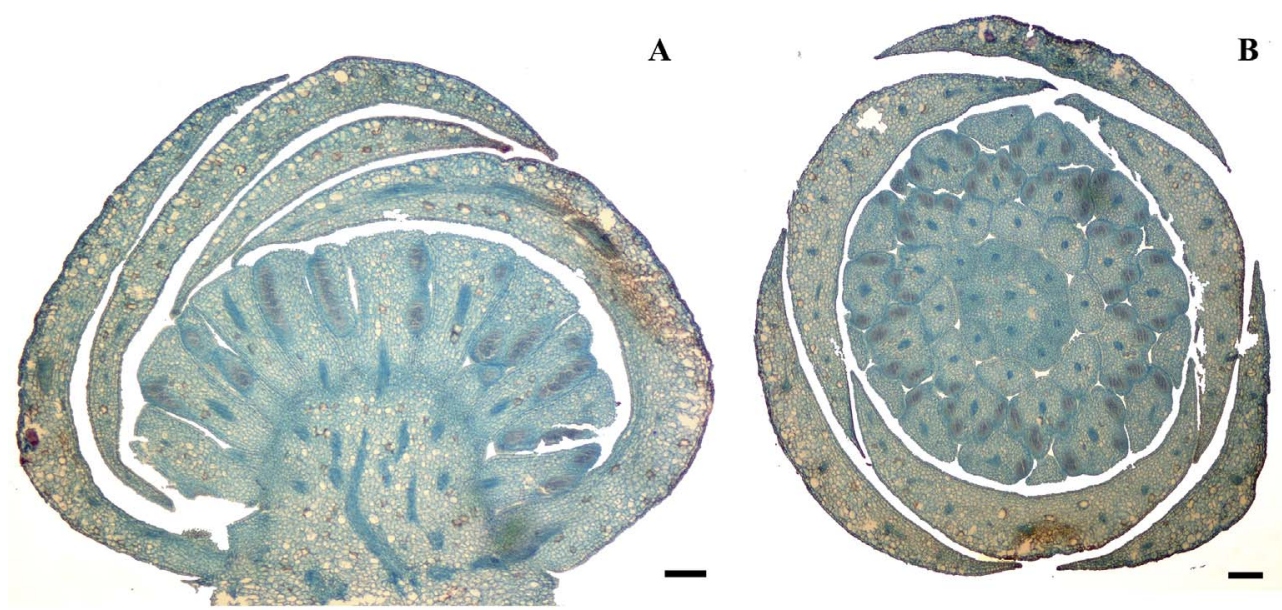

Fig. 6. Pseudoxandra spiritus-sancti. A-B. Male bud. A. longitudinal section. B. transverse section. C-G. Bisexual bud. C. transverse section. D-G Scanning electron microscopy (SEM) micrographs. D. (c) carpel, (st) stamen. E-F. staminodes. G. stamen. Bars $=100 \mu \mathrm{m}$.

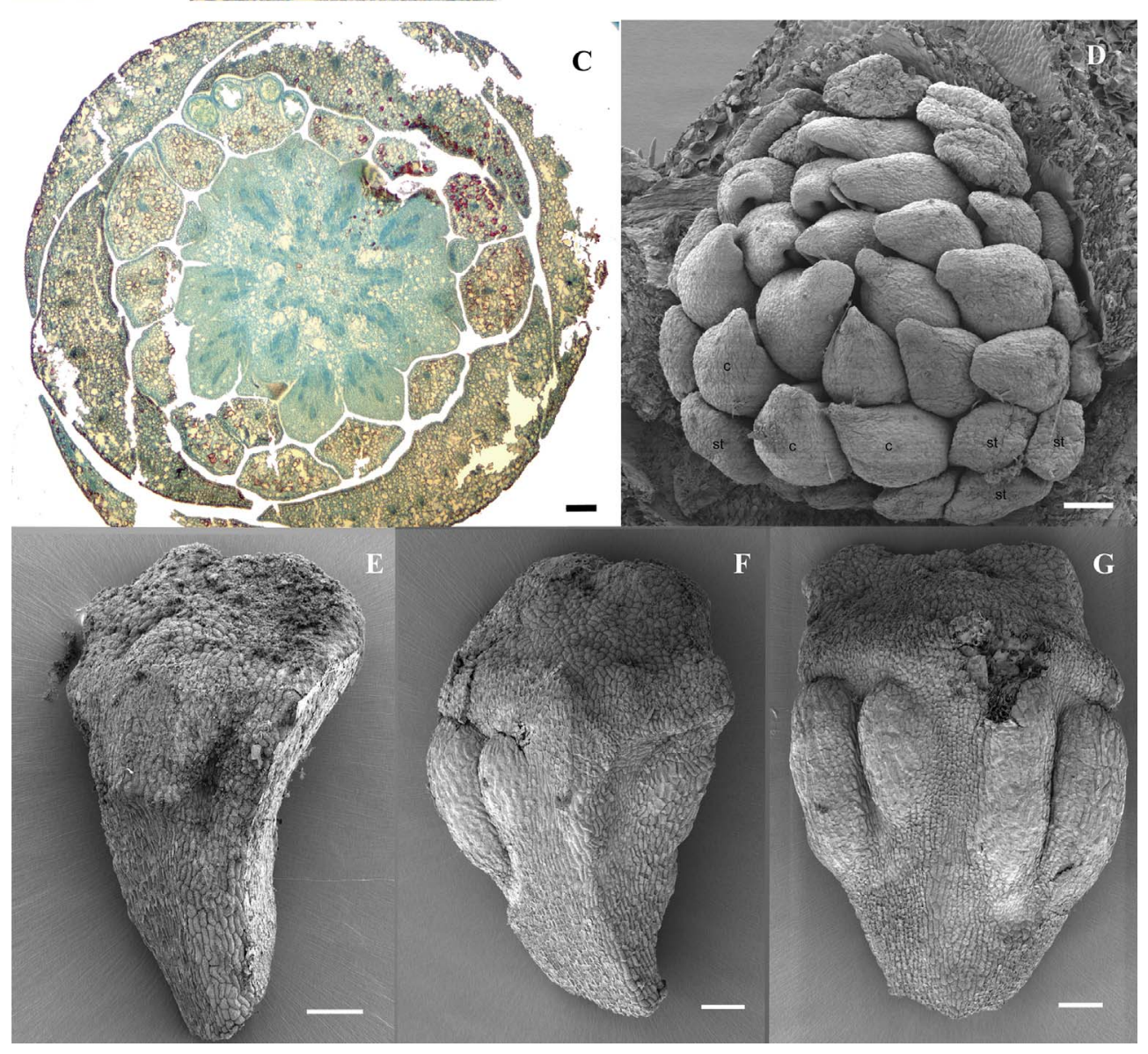

14), Malmea (node 35), Mosannona (node 23), Pseudomalmea (node 12), and Unonopsis.

Absence of staminodes is an ancestral state in Malmeeae (Fig. 5D, node 6, PP 0.99). In the entire tribe, staminodes have been reported only in $P$. spiritus-sancti. The probability of this state having arisen in the ancestor of the Pseudoxandra lineage is low (Fig. 5D, node 29, PP 0.30).

\subsection{Flower morphology}

\subsubsection{Flower morphology}

Pseudoxandra spiritus-sancti produces male and bisexual flowers on different individuals. In male flowers, around 40 stamens are arranged irregularly (Fig. 7L). Each stamen possesses two thecae and a broad filament and receives a single vascular bundle (Fig. 6B). The anther is three times as long as the filament and the connective apex is truncate
(Fig. 6A). Pistillodes were not found in longitudinal or cross sections (Fig. 6A and B). In bisexual flowers, ca 14 stamens are arranged irregularly and laterally with respect to $c a 20$ carpels, which also lack regular organization (Fig. 6C and D). Occasionally, some stamens remain non-functional, forming staminodes (Fig. 6E and F). Functional stamens have anthers twice as long as the filament, and a truncate connective apex (Fig. 6G). Each stamen is tetrasporangiate and supplied by a single vascular bundle (Fig. 7A). Carpels have a cylindrical-concave shape with a constriction at the stigma base. The stigma is long and of irregular shape (Fig. 7B); it is covered by anticlinally elongated cells of glandular appearance. Similar elongated epidermal cells also cover the merged region of the carpels and the style (Fig. 7C); they also constitute the pollen-tube transmitting tissue that extends to the ovule micropyle (Fig. 7D). Each carpel possesses an adaxial slit that differentiates early and persists until the carpel is mature (Fig. 7B). Each 

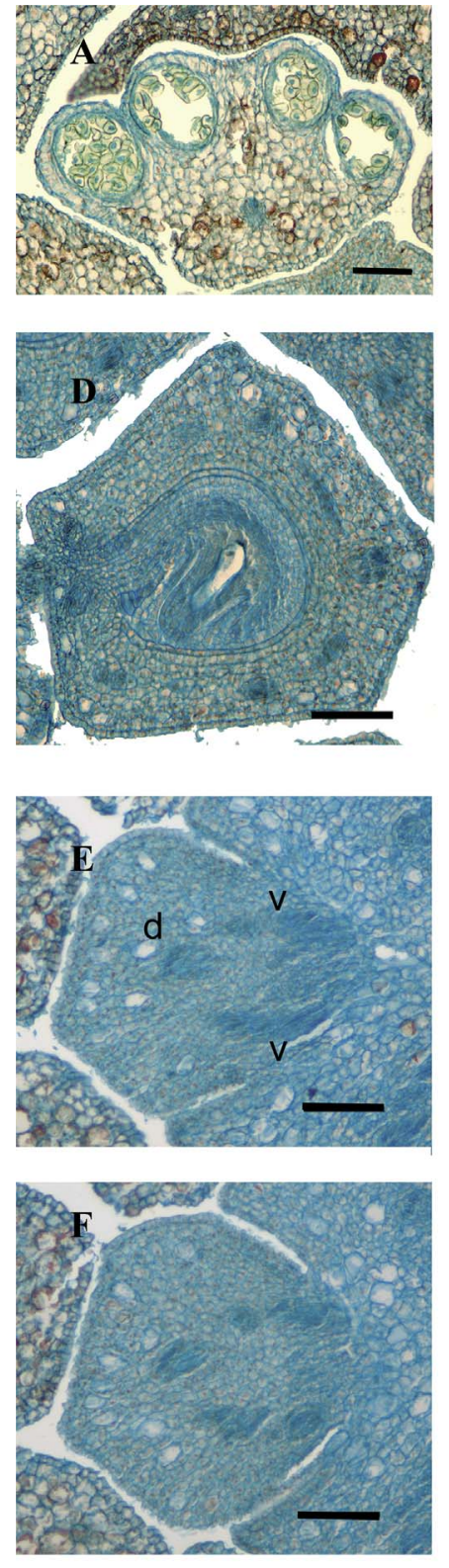
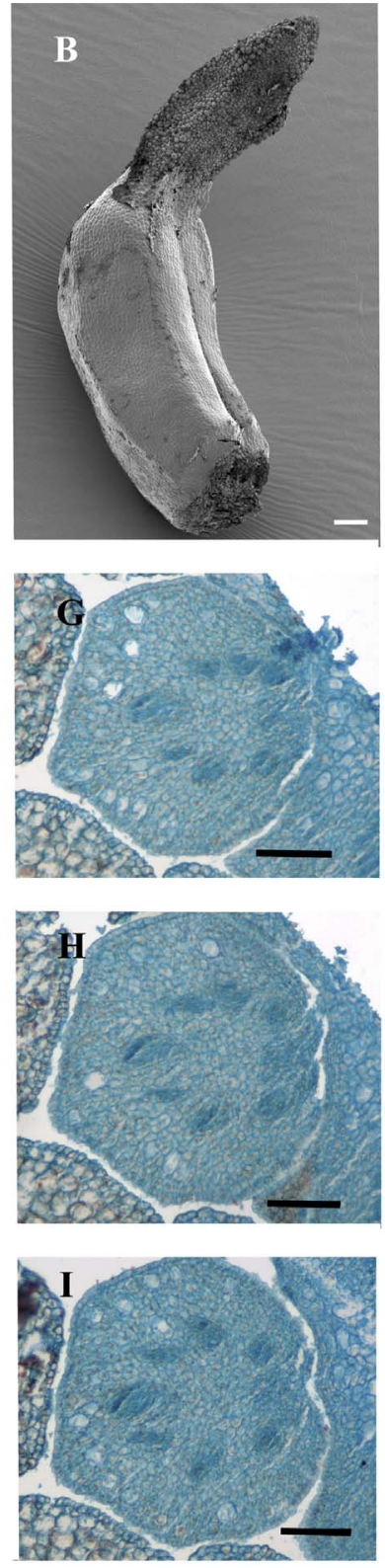
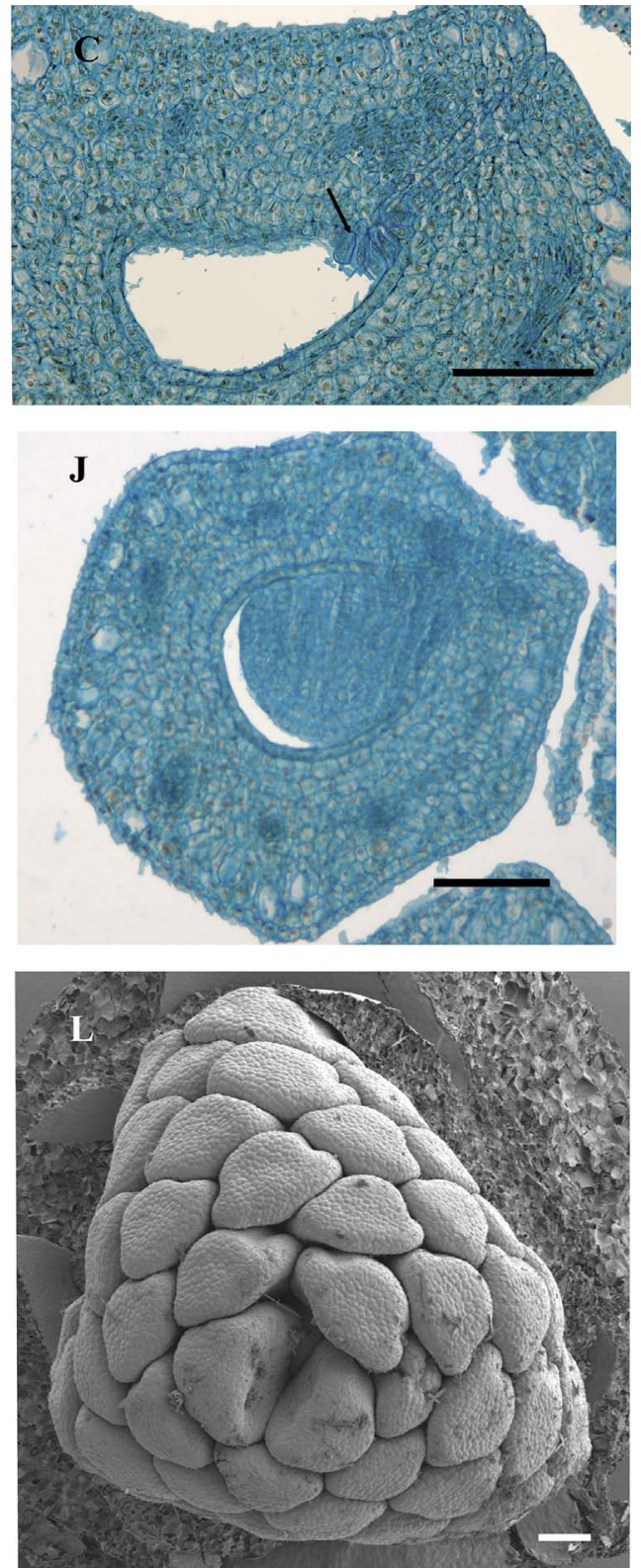

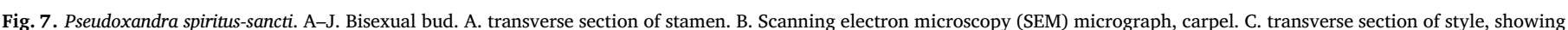

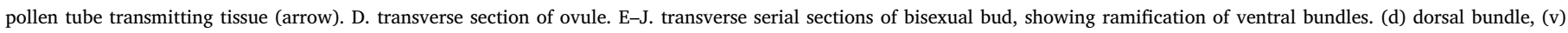
ventral bundle. H. SEM micrograph, male bud. Bars $=100 \mu \mathrm{m}$.

carpel is supplied with one dorsal and two ventral vascular bundles, both branching within the ovary wall (Fig. 7E-J). The ovule is anatropous and bitegmic. The inner integument is two-layered and the outer integument consists of 6-7 cell layers at the region opposite the funiculus (Fig. 7D).

\section{Discussion}

\subsection{Phylogenomics and evolution of androdioecy}

\subsubsection{Phylogenetic relationship}

The tribe Malmeeae was first recognized by Walker (1971), under the informal name 'Malmea tribe', based on the columellar-monosulcate pollen grains, with similar delimitation apart from the inclusion of Annickia, which is now classified in tribe Piptostigmateae (Chatrou et al., 2012). Malmeeae was recovered as monophyletic by Pirie et al. (2006), including 13 genera. Three major groups are recognized in the tribe, although the relationships among them are unclear (Pirie et al.,
2006, matrix 1). One is a clade in which Bocageopsis and Onychopetalum are sister to Unonopsis, the second contains Cremastosperma and Pseudoxandra, together sister to Malmea. The third clade includes all the remaining genera, relationships among which are not fully resolved; Mosannona is sister to Ephedranthus, Klarobelia, Oxandra, Pseudephedranthus, Pseudomalmea, and Ruizodendron (Pirie et al., 2006, matrix 1, Couvreur et al., 2011; Chatrou et al., 2012). Moreover, the monophyly of Pseudoxandra received low support (Pirie et al., 2006, matrix 1).

Our results show different phylogenetic relationships (Pirie et al., 2006, matrix 1 and 2) and improved resolution among the genera of tribe Malmeeae (Chatrou et al., 2012). The main difference is the relationships between the three main groups in tribe Malmeeae. In our analyses (Malmea (Cremastosperma, Pseudoxandra)) has emerged as sister to the rest of the tribe (1.0 BI, $86 \% \mathrm{ML}, 87 \% \mathrm{MP}$ ), the same result was also recovered by Hoekstra et al. (2017). The phylogenetic reconstruction of Pirie et al. (2006; matrix 2) shows the Unonopsis, Bocageopsis and Onychopetalum clade sister to the remaining genera. $\mathrm{Cre}$ mastosperma and Pseudoxandra are confirmed as sister groups (Chatrou 
et al., 2012; Pirie et al., 2006), and the monophyly of Pseudoxandra is well supported, the increase of data providing a better result in this respect. The sister group relationship between Klarobelia and Pseudephedranthus has been recovered (Chatrou et al., 2012; Pirie et al., 2006). Pseudomalmea, of uncertain position in Chatrou et al. (2012), is now sister to Klarobelia and Pseudephedranthus, with high support in BI analysis.

Despite these improvements, the use of 66 chloroplast molecular markers was not sufficient to resolve the position of Oxandra venezuelana. The use of low-copy nuclear genes, which can prove rich in phylogenetic information (Sang, 2002), could be a solution in future studies. A successful strategy adopted in our analysis was the inclusion of six species with only three out of 66 molecular markers sampled. Adding taxa with incomplete data is an important issue in phylogenetic analysis (Wiens and Tiu, 2012). Computational simulations with the addition of taxa with up to $90 \%$ of missing data have proven to benefit the accuracy of analyses in Bayesian, Maximum Likelihood and Parsimony approaches (Wiens and Tiu, 2012). Bayesian and Likelihood analyses showed better results in accuracy than Parsimony when adding $75 \%$ more samples with only $10 \%$ of complete data to the analyses (Wiens and Tiu, 2012). However, the paucity of data for Klarobelia cauliflora and Oxandra venezuelana, with only $5 \%$ of complete data, could explain their uncertain phylogenetic affinity (Figs. 2, S3, and 3).

\subsubsection{Ancestral state evolution analysis}

4.1.2.1. Evolution of androdioecy. The phylogenetic relationship among Ephedranthus, Klarobelia, Pseudephedranthus and Pseudomalmea, genera of which all species are androdioecious, varies in each phylogeny already published (Pirie et al., 2006; Couvreur et al., 2011; Chatrou et al., 2012). Moreover, Oxandra martiana R.E.Fr., which is an androdioecious species (Fries, 1931), has not been sampled in any phylogenetic analysis so far (Pirie et al., 2006; Couvreur et al., 2011, Chatrou et al., 2012). Our improvements in the phylogenetic relationships among genera in Malmeeae and the inclusion of Oxandra martiana in the analyses made it possible to hypothesize the evolution of androdioecy in tribe Malmeeae.

Hermaphroditism is ancestral in Malmeeae, as in many other Annonaceae (Saunders, 2010). Our results reveal that presence of male flowers is homoplastic in the tribe and has appeared four or five times independently, depending on the analysis considered (Figs. 3 and 4A). Nevertheless, androdioecy is a synapomorphy of at least two groups, one formed by Klarobelia, Pseudephedranthus, and Pseudomalmea, with 14 species, and of Ephedranthus, with seven species (Chatrou, 1998, Lopes and Mello-Silva, in prep.). An independent evolution of androdioecy has also been observed in Pseuduvaria, an Asian dioecious genus of Annonaceae (Su et al., 2008). Although both Pseuduvaria (Miliuseae) and Malmeeae both belong in Malmeoideae, androdioecy has different origins in the two groups. In Pseuduvaria it is derived from dioecy and in Malmeeae from hermaphroditism. In contrast, in Fraxinus (Oleaceae), a woody genus that also has plesiomorphic hermaphroditism, the evolution to androdioecy occurred only once and acted as an intermediate step to the evolution of dioecy (Wallander, 2008). Some authors (Bawa, 1980; Charlesworth, 1984; Wolf and Takebayashi, 2004) have hypothesized the evolution of androdioecy as an intermediate step to dioecy, as illustrated by Fraxinus, but well-authenticated cases have not been reported (Barrett, 2002). This postulated transition is not the case in Malmeeae, in which dioecy has not been reported.

Thus, the evolution of androdioecy in Malmeeae is an exceptional case, because it is neither derived from dioecy nor an intermediate step to the evolution of dioecy, but rather derived from hermaphroditism. An explanation that cannot be discarded is that the bisexual flowers are here acting as female flowers, with androdioecious species being functionally dioecious (Lloyd, 1979). However, our results in Pseudoxandra spiritus-sancti show that bisexual flowers produce pollen, so $P$. spiritus-sancti does not act as a functionally dioecious species.
4.1.2.2. Evolution of morphological features. Characters found only in (Malmea (Cremastosperma, Pseudoxandra)) are a lobed stigma (7), an autapomorphy of Cresmastosperma (Pirie, 2005, Figs. 3 and 5A) and the presence of staminodes (8) in a single species of Pseudoxandra (Figs. 3 and 5D). Staminodes are present in few genera of Annonaceae, notably in Anaxagorea, the sister genus to the rest of the family (Chatrou et al., 2012; van Heusden, 1992). Staminodes are also present in Eupomatiaceae, the sister family of Annonaceae (The Angiosperm Phylogeny Group, 2016; Endress, 1984). Our ancestral state analysis is limited with respect to outgroups and has estimated the absence of staminodes as ancestral in Malmeeae. However, there are three alternative optimizations of this character within Magnoliales, and the presence of staminodes in Pseudoxandra spiritus-sancti could be either a reversal or a convergence.

Within Malmeeae, valvate petals are found only in Unonopsis, Bocageopsis, and Onychopetalum. Petal aestivation was one of the main characters used to delimit groups in past informal classifications of Annonaceae (Koek-Noorman et al., 1990; Chatrou et al., 2012). In Malmeeae, imbricate petals (character 4) is the ancestral state, and the transition to valvate petals is a synapomorphy of Unonopsis, Bocageopsis, and Onychopetalum group (Figs. 3 and 4D). Furthermore, the presence of many flowers (3) and a cylindrical stigma (6) are also synapomorphies of the latter group (Figs. 3, 4C and 5A). Bocageopsis and Onychopetalum are sister genera that share carpels with two to five ovules (5), a unique novelty within the tribe (Maas et al., 2007, Figs. 3 and $5 \mathrm{~B})$.

A convex or raised midrib (2), another feature that has been traditionally used to recognize Bocageopsis, Onychopetalum, and Unonopsis (Maas et al., 2007), emerges as a synapomorphy of the clade that includes all genera except Malmea, Cremastosperma, and Pseudoxandra (Chatrou, 1998; Maas et al., 2007; Oliveira and Sales, 1999, Figs. 3 and 4B). However, the evolution of this feature in the tribe is complex, with many reversals. The oxandra euneura group has a convex midrib, the only exception being $O$. espintana, and the oxandra laurifolia group possess impressed to flat midribs (Figs. 3 and 4B, nodes 15 and 20). Oxandra nitida R.E.Fr., included in the oxandra euneura group, has a convex midrib, and O. sphaerocarpa R.E.Fr. and O. xylopioides Diels, belonging to the oxandra laurifolia group, has an impressed to flat midrib. Thus, the evolution of a convex midrib is a synapomorphy of the oxandra euneura group. Another traditionally important feature in previous classifications of Annonaceae, and in the recognition of Oxandra, is the stamen shape (Prantl, 1891; van Heusden, 1992; Junikka et al., 2016). A narrow stamen with a tongue-like connective, found in Oxandra and other Malmeeae, is ancestral for the tribe.

The two groups of Oxandra are also supported by differences in seed ruminations, which is spiniform in the oxandra laurifolia group, and peg-shaped in the oxandra euneura group, except in $O$. polyantha, with spiniform rumination (character 9:2; Fig. 3). The group that includes the oxandra euneura group, ((Ruizodendron ovale, Oxandra venezuelana) ((Pseudomalmea diclina (Pseudephedranthus fragrans, Klarobelia inundata)) oxandra euneura group)), has lamellate rumination as the ancestral state (Fig. 3). Ruizodendron is hermaphrodite and its eccentrically stipitate monocarps are unique in the tribe (Erkens et al., 2017). An isolated species of the genus Oxandra, O. venezuelana, has an uncertain position. Since Oxandra is polyphyletic and the oldest genus name in the tribe, nomenclatural changes would be needed in order to recover the monophyly of Oxandra. Unfortunately, the type species of the genus, Oxandra lanceolata (Sw.) Baill., has not been sampled.

\subsection{Flower morphology}

Staminodes are rarely found in Annonaceae and do not display the same functions as in other Magnoliales, such as pollinator attraction, glandular secretion or prevention of selfing (Endress, 1984). Staminodes are sometimes present in Anaxagorea (Maas and Westra, 1984, 1985), Monanthotaxis (Guo et al., 2017), Fusaea (Chatrou and He, 
1999), Miliusa (Chaowasku et al., 2013) Orophea (Kessler, 1988), Uvaria (Zhou, 2010), and Xylopia (e.g. Johnson et al., 2017), all genera with bisexual flowers, and in the female flowers of Pseuduvaria ( $\mathrm{Su}$ and Saunders, 2006). The absence of pistillodes in Annonaceae could be explained by the lack of synorganization in the flower that allow carpels to be replaced by stamens. The transition between androecium to gynoecium is not commonly marked (Xu and De Craene, 2010). Male flowers of $P$. spiritus-sancti are unisexual from inception (type II flower, Mitchell and Diggle, 2005) because there are no vestiges of pistillodes.

In both male and bisexual flowers of $P$. spiritus-sancti, the gynoecial and androecial organs are not clearly organized into whorls, particularly close to the receptacle centre (Figs. 6D and 7L). This pattern of irregular or chaotic phyllotaxis in Annonaceae is probably derived developmentally from whorled phyllotaxis. Its origin in the family is probably due to organ doubling, i.e., two structures initiated instead of a single one (Endress and Doyle, 2007). Doubling has been reported in many genera of Annonaceae, such as Anaxagorea, Cananga, Desmos, Fissistigma, Mitrephora, Miliusa, Orophea, Polyalthia, Popowia, and Pseuduvaria (Endress and Amstrong, 2011, Ronse De Craene and Smets, 1990, Xu and De Craene, 2010). As already described for other Annonaceae (Endress and Amstrong, 2011, Periasamy and Swamy, 1956), the carpels of $P$. spiritus-sancti are each supplied with three vascular bundles, one dorsal and two ventral. The ventral bundles branch and merge with the dorsal bundle (Fig. 7E-J).

Pseudoxandra spiritus-sancti is the first androdioecious taxon of tribe Malmeeae to have both flowers types described in anatomical and morphological details. It is also the only species with staminodes in tribe Malmeeae. These results represent a first step to the understanding of the floral morphology in androdioecious species in the Neotropical Annonaceae.

\section{Conclusions}

The tribe Malmeeae is composed of three main groups, Oxandra is polyphyletic and composed of two main groups of species plus Oxandra venezuelana, sister either to Ruizodendron or to Ephedranthus. Thus, a potential taxonomic solution for the polyphyly of Oxandra would be sinking all those small and weakly delimited genera of (oxandra laurifolia group ((( (Pseudephedranthus, Klarobelia inundata) Pseudomalmea) oxandra eunera group) (Ruizodendron, Oxandra venezuelana))) into a broad delimited Oxandra (Backlund and Bremer, 1998). A taxonomic revision and a phylogenetic reconstruction, including a broader sample of Oxandra species, have been initiated (Junikka et al., 2016, Zwartsenberg et al., unpublished data). Both taxonomic and phylogenetic results will bring new information for a more reasoned decision.

Hermaphroditism is plesiomorphic in the tribe, with four independent evolutions to androdieocy, which is a synapomorphy of ((Pseudephedranthus, Klarobelia) Pseudomalmea), that includes 14 species, and of Ephedranthus, with seven species. The other two independent origins are autapomorphies of Oxandra martiana and Pseudoxandra spiritus-sancti. The possibility of androdioecy being in fact a functional dioecy should be considered. Despite our morphological results for $P$. spiritus-sancti, showing bisexual flowers with functional stamens and male flowers without pistillodes, it is necessary to investigate whether both male and hermaphrodite individuals produce offspring. Further comparative investigations are necessary to understand how androdioecy is displayed in each of the two main androdioecious clades in Malmeeae; this crucial information will shed more light on the evolution of androdioecy in woody plants with hermaphrodite ancestors.

\section{Acknowledgments}

The authors thanks to Fundação de Amparo à Pesquisa do Estado de São Paulo (FAPESP) and Alberta Mennega Foundation for the financial support (2014/09131-3). Lopes and Mello-Silva thanks FAPESP for
Lopes' PhD scholarship in Brazil, The Netherlands, and England (Grants 2013/04902-9 and 2014/09366-0). Lopes thanks Instituto de Biocências, from Universidade de São Paulo, Biosystematics group, from Wageningen University and Research, and the Jodrell Laboratory, Royal Botanic Gardens, Kew, where this work was performed and the curators of the following herbaria K, L, S and SPF for allowing the study of the collection. Thanks to Sara van der Kerke and Lidija Berke for help with bioinformatics analyses, Luiz Henrique Martins Fonseca and Annelise Frazão with phylogenetic analyses, Juliana Lovo with floral morphological analyses, Adriana Quintella Lobão, Lúcia Garcez Lohmann, Alexandre Zuntini, André Olmos Simões, and Diego Demarco for useful comments in the manuscript/thesis and, the two anonymous reviewers for their helpful suggestions.

\section{Appendix A. Supplementary material}

Supplementary data associated with this article can be found, in the online version, at http://dx.doi.org/10.1016/j.ympev.2017.10.020.

\section{References}

Altschul, S.F., Gish, W., Miller, W., Myers, E.W., Lipman, D.J., 1990. Basic local alignment search tool. J. Mol. Biol. 215, 403-410.

Backlund, A., Bremer, K., 1998. To be or not to be - principles of classification and monotypic plant families. Taxon 47, 391-400.

Bakker, F.T., Lei, D., Yu, J., Mohammadin, S., Wei, Z., van de Kerke, S., Gravendeel, B., Nieuwenhuis, M., Staats, M., Alquezar-Planas, D.E., Holmer, R., 2016. Herbarium genomics: plastome sequence assembly from a range of herbarium specimens using an Iterative Organelle Genome Assembly pipeline. Biol. J. Lin. Soc. 117, 33-43.

Barrett, S.C.H., 2002. The evolution of plant sexual diversity. Nat. Rev. Genet. 3, 274-284.

Bawa, K.S., 1980. Evolution of dioecy in flowering plants. Annu. Rev. Ecol. Evol. Syst. 11, 15-39.

Bawa, K.S., Beach, J.H., 1981. Evolution of sexual systems in flowering plants. Ann. Mo. Bot. Gard. 68, 254-274.

Chaowasku, T., Kessler, P.J.A., Chatrou, L.W., 2013. Phylogeny of Miliusa (Magnoliales: Annonaceae: Malmeoideae: Miliuseae), with descriptions of two new species from Malesia. Eur. J. Taxon. 54, 1-21.

Charlesworth, D., 1984. Androdioecy and the evolution of dioecy. Bot. J. Linn. Soc. 22, 333-348.

Chatrou, L.W., 1997. Studies in Annonaceae XXXII. A peculiar new species of Malmea (Annonaceae) from Panama and Colombia. Novon 7, 346-349.

Chatrou, L.W., 1998. Changing genera. Systematic studies in Neotropical and West African Annonaceae. Ph.D. Thesis. Utrecht University, Utrecht.

Chatrou, L.W., He, P., 1999. Studies in Annonaceae XXXIII. A revision of Fusaea (Baill.) Saff. Brittonia 51, 181-203.

Chatrou, L.W., Pirie, M.D., Erkens, R.H.J., Couvreur, T.L.P., Neubig, K.M., Abbott, J.R., Mols, J.B., Maas, J.W., Saunders, R.M.K., Chase, M.W., 2012. A new subfamilial and tribal classification of the pantropical flowering plant family Annonaceae informed by molecular phylogenetics. Bot. J. Linn. Soc. 169, 5-40.

Chen, B.L., Nooteboom, H.P., 1993. Notes on Magnoliaceae III: The Magnoliaceae of China. Ann. Mo. Bot. Gard. 80, 999-1104.

Clark, S.C., Egan, R., Frazier, P.I., Wang, Z., 2013. ALE: a generic assembly likelihood evaluation framework for assessing the accuracy of genome and metagenome assemblies. Bioinformatics 29, 435-443.

Couvreur, T.L.P., Pirie, M.D., Chatrou, L.W., Saunders, R.M.K., Su, Y.C.F., Richardson, J.E., Erkens, R.H.J., 2011. Early evolutionary history of the flowering plant family Annonaceae: steady diversification and boreotropical geodispersal. J. Biogeogr. 38, 664-680.

Di Stilio, V.S., Kramer, E.M., Baum, D.A., 2005. Floral MADS box genes and homeotic gender dimorphism in Thalictrum dioicum (Ranunculaceae) - a new model for the study of dioecy. Plant J. 41, 755-766.

Diggle, P.K., Di Stilio, V.S., Gschwend, A.R., Golenberg, E.M., Moore, R.C., Russell, J.R.W., Sinclair, J.P., 2011. Multiple developmental processes underlie sex differentiation in angiosperms. Trends Genet. 27, 368-376.

Doyle, J.J., Doyle, J.L., 1987. A rapid DNA isolation procedure for small quantities of fresh leaf tissue. Phytochem. Bull. 19, 11-15.

Doyle, J.A., Le Thomas, A., 1996. Phylogenetic analysis and character evolution in Annonaceae. Bulletin du Muséum National d'Histoire Naturelle, Section B, Adansonia 18, 279-334.

Endress, P.K., 1984. The role of inner staminodes in the floral display of some relic Magnoliales. Plant Syst. Evol. 146, 269-282.

Erkens, R.H.J., Oosterhof, J., Westra, L.Y.T., Maas, P.J.M., 2017. Revisions of Ruizodendron and Pseudephedranthus (Annonaceae) including a new species and an overview of most up-to-date revisions of Neotropical Annonaceae genera. PhytoKeys 86, 75-96.

Endress, P.K., Doyle, J.A., 2007. Floral phyllotaxis in basal angiosperms: development and evolution. Curr. Opin. Plant Biol. 10, 52-57.

Endress, P.K., Amstrong, J.E., 2011. Floral development and floral phyllotaxis in 
Anaxagorea (Annonaceae). Ann. Bot. 108, 835-845.

Fries, R.E., 1931. Revision der Arten einiger Annonaceen-Gattungen II. Acta Horti Bergiani 10, 129-341.

Goloboff P.A., Farris J.S., Nixon K.C., 2003. T.N.T.: Tree Analysis Using New Technology. $<$ lillo.org.ar/phylogeny/tnt $>$.

Guo, X., Hoekstra, P.H., Tang, C.C., Thomas, D.C., Wieringa, J.J., Chatrou, L.W., Saunders, R.M.K., 2017. Cutting up the climbers: evidence for extensive polyphyly in Friesodielsia (Annonaceae) necessitates generic realignment across the tribe Uvarieae. Taxon 66, 3-19.

Hoekstra, P.H., Wieringa, J.J., Smets, E., Brandão, R.D., Lopes, J.C., Erkens, R.H.J., Chatrou, L.W., 2017. Correlated evolutionary rates across genomic compartments in Annonaceae. Mol. Phylogenet. Evol. 114, 63-72.

Ishida, K., Hiura, T., 1998. Pollen fertility and flowering phenology in an androdioecious tree, Fraxinus lanuginosa (Oleaceae), in Hokkaido, Japan. Int. J. Plant Sci. 159, 941-947.

Johnson, D.M., Luke, Q., Goyder, D.J., Murray, N.A., 2017. New species of Xylopid (Annonaceae) from East Africa. Kew. Bull. 72, 11.

Junikka, L., Maas, P.J.M., Maas-van de Kamer, H., Westra, L.Y.T., 2016. Revision of Oxandra (Annonaceae). Blumea 61, 215-266.

Kainer, D., Lanfear, R., 2015. The effects of partitioning on phylogenetic inference. Mol. Biol. Evol. 32, 1611-1627.

Katoh, K., Misawa, K., Kuma, K., Miyata, T., 2002. MAFFT: a novel method for rapid multiple sequence alignment based on fast Fourier transform. Nucleic Acids Res. 30, 3059-3066.

Kearse, M., Moir, R., Wilson, A., Stones-Havas, S., Cheung, M., Sturrock, S., Buxton, S., Cooper, A., Markowitz, S., Duran, C., Thierer, T., Ashton, B., Mentjies, P., Drummond, A., 2012. Geneious Basic: an integrated and extendable desktop software platform for the organization and analysis of sequence data. Bioinformatics 28, 1647-1649.

Kessler, P.J.A., 1988. Revision der Gattung Orophea Blume (Annonaceae). Blumea 33, $1-80$.

Koek-Noorman, J., Westra, L.Y.T., Maas, P.J.M., 1990. Studies in Annonaceae. XIII. The role of morphological characters in subsequent classifications of Annonaceae: a comparative survey. Taxon 39, 16-32.

Lanfear, R., Calcott, B., Ho, S.Y.W., Guindon, S., 2012. PartitionFinder: combined selection of partitioning schemes and substitution models for phylogenetic analyses. Mol. Biol. Evol. 29, 1695-1701.

Lanfear, R., Calcott, B., Kainer, D., Mayer, C., Stamatakis, A., 2014. Selecting optimal partitioning schemes for phylogenomic datasets. BMC Evol. Biol. 14, 82.

Lepart, J., Dommée, B., 1992. Is Phillyrea angustifolia L. (Oleaceae) an androdioecious species? Bot. J. Linn. Soc. 108, 375-387.

Lloyd, D.G., 1975. The maintenance of gynodioecy and androdioecy in angiosperms. Genetica 45, 325-339.

Lloyd, D.G., 1979. Some reproductive factors affecting the selection of self-fertilization in plants. Am. Nat. 113, 67-79.

Lopes, Mello-Silva (in prep.). Morphological phylogenetic analysis and revision of Ephedranthus (Annonaceae).

Maas, P.J.M., Westra, L.Y.T., 1984. Studies in Annonaceae II: A monograph of the genus Anaxagorea A.St.-Hil. Botanische Jahrbücher für Systematik, Pflanzengeshichte und Pflanzengeographie 105, 73-134.

Maas, P.J.M., Westra, L.Y.T., 1985. Studies in Annonaceae II: A monograph of the genus Anaxagorea A.St.-Hil. Part 2. Botanische Jahrbücher für Systematik, Pflanzengeshichte und Pflanzengeographie 105, 145-204.

Maas, P.J.M., Westra, L.Y.T., 2003. Revision of the Neotropical genus Pseudoxandra. Blumea 48, 201-259.

Maas, P.J.M., Westra, L.Y.T., 2005. A new species of Pseudoxandra (Annonaceae). Blumea $50,61-64$

Maas, P.J.M., Westra, L.Y.T., Vermeer, M., 2007. Revision of the Neotropical genera Bocageopsis, Onychopetalum, and Unonopsis (Annonaceae). Blumea 52, 413-554.

Maddison, W.P., Maddison, D.R., 2015. Mesquite: a modular system for evolutionary analysis. Version 3, 04. <http://mesquiteproject.org $>$.

Miller M.A., Pfeiffer W., Schwartz T., 2010. Creating the CIPRES science gateway for inference of large phylogenetic trees. In: Proceedings of the Gateway Computing Environments Workshop (GCE), 14 Nov. 2010, New Orleans, pp. 1-8.

Mitchell, C.H., Diggle, P.K., 2005. The evolution of unisexual flowers: morphological and functional convergence results from diverse developmental transitions. Am. J. Bot. 92, 1068-1076.

Nixon, K.C., 1999a. The parsimony ratchet, a new method for rapid parsimony analysis. Cladistics 15, 415-428.

Nixon K.C., 1999b. Winclada (BETA) ver. 0.9.9. Published by the author, Ithaca

Oliveira, J., Sales, M.F., 1999. Estudos taxonômicos dos gêneros Ephedranthus e Pseudephedranthus Aristeg.: Annonaceae. Boletim do Museu Paraense "Emílio Goeldi”. Nova série, Botânica 15, 117-166.

Pagel, M., Meade, A., Barker, D., 2004. Bayesian estimation of ancestral character states on phylogenies. Syst. Biol. 53, 673-684.

Pagel M., Meade, A., 2014. BayesTraits v. 2.0. Reading: University of Reading. < http:// www.evolution.rdg.ac.uk >

Pannell, J.R., 2001. A hypothesis for the evolution of androdioecy: the joint influence of reproductive assurance and local mate competition in a metapopulation. Evol. Ecol.
$14,195-211$.

Pannell, J.R., 2002. The evolution and maintenance of androdioecy. Annu. Rev. Ecol. Syst. 33, 397-425.

Periasamy, K., Swamy, B.G.L., 1956. The conduplicate carpel of Cananga odorata. J. Arnold Arboret. 37, 366-372.

Pirie M.D., 2005. Cremastosperma (and other evolutionary digressions). Molecular phylogenetic, biogeographic, and taxonomic studies in Neotropical Annonaceae. PhD Thesis. Universiteit Utrecht, Utrecht.

Pirie, M.D., Chatrou, L.W., Mols, J.B., Erkens, R.H.J., Oosterhof, J., 2006. 'Andeancentred' genera in the short-branch clade of Annonaceae: testing biogeographical hypotheses using phylogeny reconstruction and molecular dating. J. Biogeogr. 33, $31-46$.

Pontes, A.F., Barbosa, M.R.V., Maas, P.J.M., 2004. Flora Paraibana: Annonaceae Juss. Acta Botanica Brasilica 18, 281-293.

Prantl K., 1891. Anonaceae. In: Engler, A. \& Prantl, K. Die natirlichen Pflanzenfamilien, III. Teil, 2. Abteilung. Wilhelm Engelmann, Leipzig, pp. 23-39.

R Development Core Team, 2008. R: A Language and Environment for Statistical Computing. R Foundation for Statistical Computing, Vienna. < http://www.Rproject.org $>$.

Ronse De Craene, L.P., Smets, E.F., 1990. The floral development of Popowia whitei (Annonaceae). Nord. J. Bot. 10, 411-420 [correction in Nordic Journal of Botany 11 (1991): 420].

Ross, M.D., 1982. Five evolutionary pathways to subdioecy. Am. Nat. 119, 297-318.

Ronquist, F., Teslenko, M., van der Mark, P., Ayres, D., Darling, A., Höhna, S., Larget, B. Liu, L., Suchard, M.A., Huelsenbeck, J.P., 2012. MrBayes 3.2: efficient Bayesian phylogenetic inference and model choice across a large model space. Syst. Biol. 61, 539-542.

Safford, W.E., 1916. Desmopsis, a new genus of Annonaceae. Bull. Torrey Bot. Club 43, 183-193.

Sang, T., 2002. Utility of low-copy nuclear gene sequences in plant phylogenetics. Crit. Rev. Biochem. Mol. Biol. 37, 121-147.

Saunders, R.M.K., 2010. Floral evolution in the Annonaceae: hypotheses of homeotic mutations and functional convergence. Biol. Rev. 85, 571-591.

Simmons, M.P., 2014. Limitations of locally sampled characters in phylogenetic analyses of sparse supermatrices. Mol. Phylogenet. Evol. 74, 1-14.

Stamatakis, A., Hoover, P., Rougemont, J., 2008. A rapid bootstrap algorithm for the RAxML web servers. Syst. Biol. 57, 758-771.

Stamatakis, A., 2014. RAxML Version 8: A tool for phylogenetic analysis and post-analysis of large phylogenies. Bioinformatics 30, 1312-1313.

Su, Y.C.F., Saunders, R.M.K., 2006. Monograph of Pseuduvaria (Annonaceae). Syst. Bot. Monogr. 79, 1-204.

Su, Y.C.F., Smith, G.J.D., Saunders, R.M.K., 2008. Phylogeny of the basal angiosperm genus Pseuduvaria (Annonaceae) inferred from five chloroplast DNA regions, with interpretation of morphological character evolution. Mol. Phylogenet. Evol. 48, 188-206.

Sugiura, N., 1978. Further analysis of the data by Akaike's information criterion and the finite corrections. Commun. Stat. - Theory Methods A7, 13-26.

The Angiosperm Phylogeny Group, 2016. An update of the Angiosperm Phylogeny Group classification for the orders and families of flowering plants: APG IV. Bot. J. Linn. Soc. $181,1-20$

Thiers B., 2017 [continuously updated]. Index Herbariorum: A global directory of public herbaria and associated staff. New York Botanical Garden's Virtual Herbarium. < http://sweetgum.nybg.org/ih/ >

Vaidya, G., Lohman, D.J., Meier, R., 2011. SequenceMatrix: concatenation software for the fast assembly of multi-gene datasets with character set and codon information. Cladistics 27, 171-180.

van Heusden, E.C.H., 1992. Flowers of Annonaceae: morphology, classification, and evolution. Blumea 7 (Supplement), 1-218.

van Setten, A.K., Koek-Noorman, J., 1992. Studies in Annonaceae. XVII. Fruits and seeds of Annonaceae: morphology and its significance for classification and identification. Biblioth. Bot. 142, 1-101.

Wallander, E., 2008. Systematics of Fraxinus (Oleaceae) and evolution of dioecy. Plant Syst. Evol. 273, 25-49.

Walker, J.W., 1971. Pollen morphology, phytogeography, and phylogeny of the Annonaceae. Contribut. Gray Herbari. Harvard Univ. 202, 1-132.

Westra, L.Y.T., Maas, J.P.M., 2012. Tetrameranthus (Annonaceae) revisited including a new species. PhytoKeys 12, 1-21.

Wiens, J.J., Tiu, J., 2012. Highly incomplete taxa can rescue phylogenetic analyses from the negative impacts of limited taxon sampling. PLoS ONE 7, e42925.

Wolf, D.E., Takebayashi, N., 2004. Pollen limitation and the evolution of androdioecy from dioecy. Am. Nat. 163, 122-137.

Xu, F., De Craene, L.R., 2010. Floral ontogeny of Annonaceae: evidence for high variability in floral form. Ann. Bot. 106, 591-605.

Zhou L., 2010. Systematics and phylogenetics of Uvaria (Annonaceae): origin, dispersal and morphological diversification of a major Palaeotropical lineage. PhD Thesis. The University of Hong Kong.

Zhou, X.-J., Ma, L., Liu, W.-Z, 2016. Functional androdioecy in the rare endemic tree Tapiscia sinensis. Bot. J. Linn. Soc. 180, 504-514. 